UNIVERSIDADE FEDERAL DE VIÇOSA

MARIA CAROLINA COSTA ALMEIDA ZEFERINO

AÇÃO DO MERCÚRIO NA GERMINAÇÃO DE SEMENTES DE Melanoxylon brauna Schott. (FABACEAE-CAESALPINOIDEAE) 
MARIA CAROLINA COSTA ALMEIDA ZEFERINO

AÇÃO DO MERCÚRIO NA GERMINAÇÃO DE SEMENTES DE Melanoxylon brauna Schott. (FABACEAE-CAESALPINOIDEAE)

Dissertação apresentada à Universidade Federal de Viçosa, como parte das exigências do Programa de Pós-Graduação em Ciência Florestal, para obtenção do título de Magister Scientiae.

Orientador: Eduardo Euclydes de L. e Borges Coorientadora: Genaina Aparecida de Souza 
Ficha catalográfica elaborada pela Biblioteca Central da Universidade Federal de Viçosa - Campus Viçosa

$\mathrm{T}$

Zeferino, Maria Carolina Costa Almeida, 1994-

Z43a

Ação do mercúrio na germinação de sementes de

2021 Melanoxylon brauna Schott. (Fabaceae-Caesalpinoidae) / Maria

Carolina Costa Almeida Zeferino. - Viçosa, MG, 2021.

1 dissertação eletrônica (53f.): il. (algumas color.).

Orientador: Eduardo Euclydes de Lima e Borges.

Dissertação (mestrado) - Universidade Federal de Viçosa.

Referências bibliográficas: f. 40-53.

DOI: https://doi.org/10.47328/ufvbbt.2021.071

Modo de acesso: World Wide Web.

1. Germinação. 2. Elementos traços. 3. Toxicidade.

4. Embebição. I. Universidade Federal de Viçosa. Departamento de Engenharia Florestal. Programa de Pós-Graduação em Ciência Florestal. II. Título.

CDO adapt. CDD 634.9181528 


\section{AÇÃO DO MERCÚRIO NA GERMINAÇÃO DE SEMENTES DE Melanoxylon brauna Schott. (FABACEAE-CAESALPINOIDEAE)}

Dissertação apresentada à Universidade Federal de Viçosa, como parte das exigências do Programa de Pós-Graduação em Ciência Florestal, para obtenção do título de Magister Scientiae.

APROVADA: 08 de julho de 2021.

Assentimento:
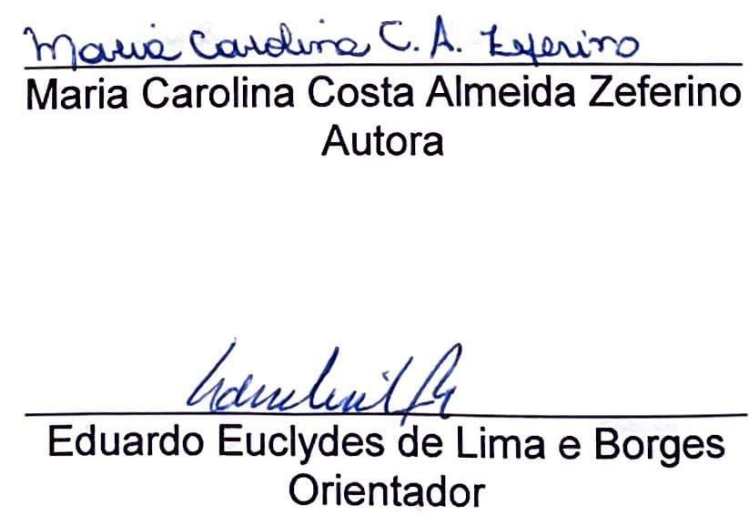


\section{AGRADECIMENTOS}

Agradeço primeiramente a Deus, por sempre me abençoar, iluminar meus passos e me dar sabedoria para seguir em frente.

Aos meus pais, José Renato e Lusmar, por todo apoio incondicional. Sem essa confiança e amor nada seria possível.

Ao meu irmão e melhor amigo Thomaz, que sempre esteve ao meu lado, independente da distância, sempre me ouvindo e aconselhando.

Ao professor Eduardo, que foi mais que um orientador, e sim um "segundo pai", que me ouviu rir e chorar incontáveis vezes, sempre com palavras confortantes. Agradeço pelas orientações acadêmicas e pelos ensinamentos que vou levar para a vida.

À Genaina, que nunca teve hora ou lugar para sanar minhas dúvidas, sempre solícita e proativa; começou como uma coorientadora e se tornou uma amiga.

À Marquione, por todo amor com que me acolheu desde o meu primeiro dia no laboratório. Ao Mauro, por sempre ser paciente e estar à disposição para me ensinar e auxiliar nos experimentos desse estudo. Aos colegas do LASF e da Silvicultura, especialmente Tiãozinho, Luciane, Rodrigo, Lydiane, Vânia, Geraldo e Gilberto.

À Gabriela Samartini, por ter sido uma irmã, sempre cuidadosa e ficando ao meu lado nos momentos mais delicados pelos quais já passei.

Às meninas do 706, Talita, Alessandra e Nathane, por dividirem a casa e a vida comigo, ouvindo os dramas do dia a dia (e não foram poucos).

À Camila e ao Guilherme por tanto acolhimento.

Aos amigos que Viçosa me proporcionou, que fizeram com que essa caminhada fosse mais feliz. E aos amigos de Manhuaçu, em especial Karina, Letícia, Luiz e André. À Universidade Federal de Viçosa e ao DEF.

À $\mathrm{CNPq}$ e à Coordenação de Aperfeiçoamento de Pessoal de Nível Superior (CAPES), pela concessão da bolsa de estudos.

A todos que me ajudaram direta e indiretamente nessa conquista: Muito obrigada!

"Senhor, uma andorinha só não faz verão." Miguel de Cervantes 


\section{RESUMO}

ZEFERINO, Maria Carolina Costa Almeida, M.Sc., Universidade Federal de Viçosa, julho de 2021. Ação do mercúrio na germinação de sementes de Melanoxylon brauna Schott. (Fabaceae-Caesalpinoidae). Orientador: Eduardo Euclydes de Lima e Borges. Coorientadora: Genaina Aparecida de Souza.

Técnicas empregadas nos meios urbano, rural e industrial são responsáveis pelo acúmulo de elementos traço no meio ambiente, comprometendo a qualidade do solo e possibilitando a entrada desses elementos na cadeia alimentar. O Mercúrio $(\mathrm{Hg})$ é considerado potencialmente tóxico à biota como um todo; nas plantas pode causar estresse hídrico, alteração hormonal, diminuição da biomassa, inibição da fotossíntese e até morte. Nas sementes, esse elemento afeta a germinação inibindo a absorção de água, além de estimular o estresse oxidativo. As sementes são o principal método pelo qual as plantas se reproduzem na natureza e são utilizadas para propagar inúmeras espécies florestais. A germinação é um estágio essencial no ciclo de vida das espécies. $O$ objetivo do presente estudo foi estabelecer a relação entre a presença do $\mathrm{Hg}$ e a germinação de sementes de Melanoxylon brauna. Avaliou-se a porcentagem de germinação, o Índice de Velocidade de Germinação, o comprimento do eixo embrionário, o consumo de reservas, a taxa de consumo de oxigênio, as atividades das enzimas $\alpha$ - e $\beta$-amilase e a produção de malonaldeído das sementes submetidas a diferentes concentrações de $\mathrm{HgCl}_{2}(25,50,75,100 \mu \mathrm{M}, 1$, 2, 3, 4 e $5 \mathrm{mM})$. De forma geral, os embriões de Melanoxylon brauna tratados com $\mathrm{HgCl}_{2}$ apresentaram redução na porcentagem de germinação e no IVG, no comprimento do eixo embrionário, no consumo de reservas, na taxa de consumo de oxigênio, nas atividades das enzimas $\alpha$ - e $\beta$-amilase e na produção de MDA. A concentração de $\mathrm{HgCl}_{2}$ de até $5 \mathrm{mM}$ não foi capaz de causar a morte das sementes, no entanto alterou a absorção de água dessas, levando ao atraso e inibição da germinação.

Palavras-chave: Elementos traços. Embebição. Cloreto de mercúrio. Toxicidade. 


\begin{abstract}
ZEFERINO, Maria Carolina Costa Almeida, M.Sc., Universidade Federal de Viçosa, July, 2021. Effect of Mercury on germination of Melanoxylon brauna Schott. (Fabaceae-Caesalpinoidae) seeds. Advisor: Eduardo Euclydes de Lima e Borges. Co-advisor: Genaina Aparecida de Souza.
\end{abstract}

Techniques used in urban, rural and industrial environments are responsible for the accumulation of trace elements in the environment, compromising the quality of the soil and allowing these elements to enter the food chain. Mercury $(\mathrm{Hg})$ is considered potentially toxic to the biota as a whole; in plants, it can cause water stress, hormonal alteration, decrease in biomass, inhibition of photosynthesis and even death. In seeds, this element affects germination by inhibiting water absorption, in addition to stimulating oxidative stress. Seeds are the main method that plants reproduce in nature and are used to propagate many forest species. Germination is an essential stage in the life cycle of species. The objective of the present study was establishing the relationship between the presence of $\mathrm{Hg}$ and the germination of Melanoxylon brauna seeds and investigate the effects of this metal on their metabolism. Germination percentage, germination speed index, embryonic axis length, reserve consumption, oxygen consumption rate, $\alpha$ - and $\beta$-amylase enzyme activities and malonaldehyde production of seeds subjected to different concentrations of $\mathrm{HgCl}_{2}$ were evaluated $(25,50,75,100 \mu \mathrm{M}, 1,2,3,4$ e 5mM). In general, Melanoxylon brauna seeds and embryos treated with $\mathrm{HgCl}_{2}$ showed a reduction in germination percentage and IVG, embryonic axis length, reserve consumption, oxygen consumption rate, $\alpha$ and $\beta$-amylase enzyme activities and MDA production. The concentration of $\mathrm{HgCl}_{2}$ up to $5 \mathrm{mM}$ did not kill seeds, however it altered their water absorption, leading to delay and inhibition of germination.

Keywords: Trace elements. Imbibition. Mercury chloride. Toxicity. 


\section{SUMÁRIO}

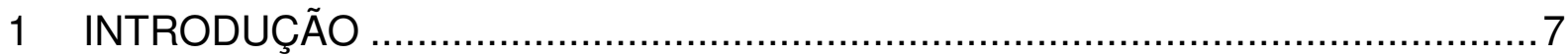

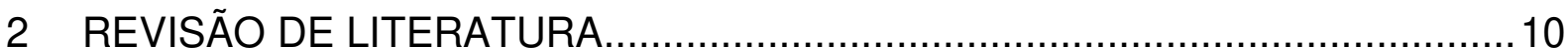

2.1 Contaminação do Meio Ambiente por Elementos Traço .......................... 10

2.2 Elementos Traço .................................................................... 11

2.3 A Toxidez do Mercúrio e Estresse Oxidativo nas Plantas............................ 12

2.4 A Importância dos Estudos sobre Germinação e Substratos...................... 13

2.5 A espécie: Melanoxylon brauna ..................................................... 15

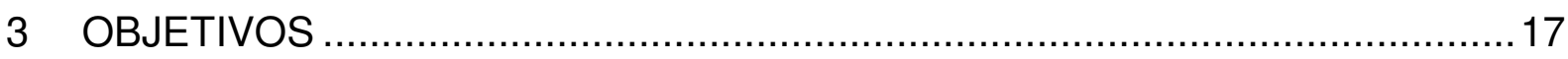

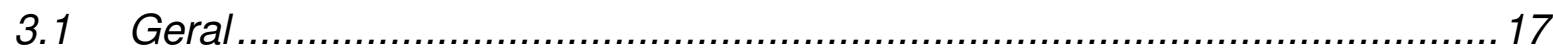

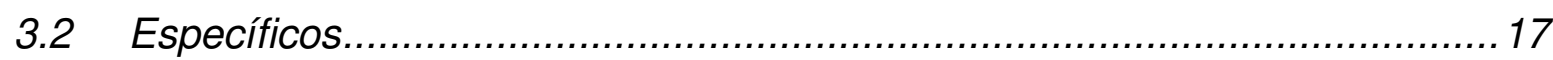

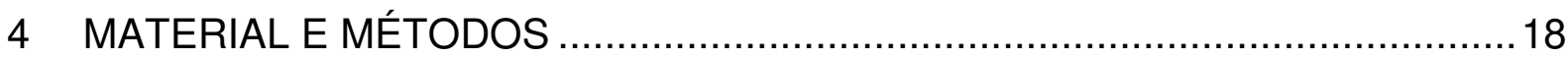

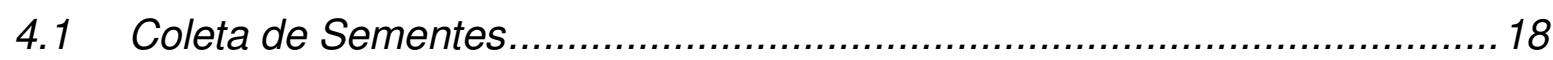

4.2 Teste de Germinação e IVG das Sementes ...................................... 18

4.3 Testes de Concentrações das Soluções de Mercúrio................................. 18

4.4 Desponte e Vácuo nas Sementes .................................................. 18

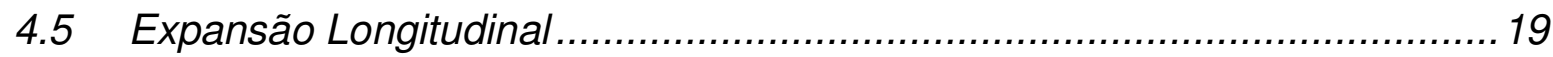

4.6 Teste de Embebição e Curva de Hidratação ........................................... 19

4.7 Análise Anatômica ................................................................... 19

4.8 Mobilização de Reservas ...........................................................20

4.9 Atividade das Enzimas $\alpha$-amilase e $\beta$-amilase ....................................21

4.10 Determinação da Concentração de Malonaldeído ...................................21

4.11 Análise da Atividade Respiratória e Verificação da Morte Celular

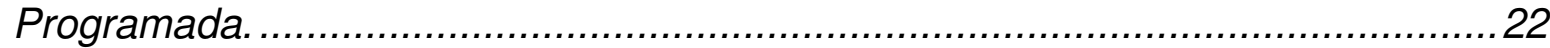

4.12 Delineamento Experimental e Análises Estatísticas ...............................22

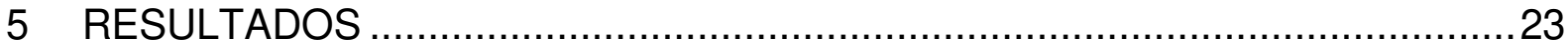

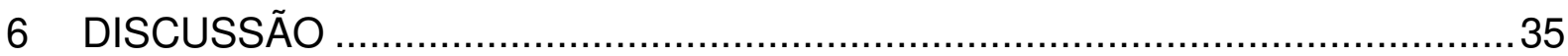

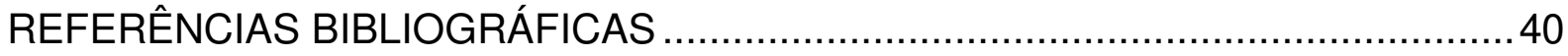




\section{INTRODUÇÃO}

A degradação ambiental tornou-se uma consequência marcante e preocupante do aumento da população e do desenvolvimento industrial e agrícola (LIANG \& YANG, 2019). Diversas práticas usuais nos meios urbano, rural e industrial são responsáveis pelo acúmulo de resíduos tóxicos no solo. Em consequência, aumentou-se também a preocupação sobre a toxicidade dos compostos conhecidos como "metais pesados" (YUAN et al., 2019).

O termo "metal pesado", hoje em dia também denominado de "elemento traço", está atrelado à poluição e à toxidez (SHANG et al., 2019). Entretanto, deve-se diferenciar os elementos essenciais ao metabolismo dos seres vivos, como zinco, cobre, manganês e ferro, daqueles que são essencialmente tóxicos, por exemplo o cádmio, chumbo, arsênio e o mercúrio (KHANAM et al., 2020). Visto que, além de não exercerem funções nos organismos, podem ser altamente prejudiciais, e até mesmo letais (DAVENPORT, 2020).

Amplo uso dos metais pesados pela indústria (siderurgia, mineração, galvanização, eletrônica) e na agricultura contaminou o solo, estando entre os problemas ambientais atuais. Principalmente na agricultura, a aplicação de fungicidas e práticas adotadas para corrigir o solo são comuns no Brasil. Muitas vezes, essas negligenciam o fato de que as concentrações de elementos traço presentes nesses compostos serão altamente prejudiciais à biota (YUAN et al., 2017; LI et al., 2018).

Atividades como a mineração e a agricultura podem dizimar, parcial ou completamente a cobertura vegetal do solo. A remoção dessa cobertura pode levar, eventualmente, à erosão do solo. Além disso, resíduos tóxicos podem ser carreados até os lençóis freáticos e aumentar os níveis de elementos traço nos sistemas (MINARI et al., 2017; YANG et al., 2018). Um elemento traço que se destaca pela sua alta toxicidade é o mercúrio $(\mathrm{Hg})$. Além da capacidade de se movimentar na água e no solo, o $\mathrm{Hg}$ pode ser absorvido pelas plantas, acumulado e transferido ao longo da cadeia trófica (GUPTA et al., 2019). Esse elemento é considerado potencialmente tóxico à biota como um todo, até mesmo em baixas concentrações (CLEMENS \& MA, 2016; AZZAM et al., 2016).

Os elementos traço afetam a germinação das sementes pela inibição da absorção da água, sendo altamente eficazes em inibir as atividades das aquaporinas nas sementes e nos eixos embrionários (CARDOSO et al., 2015; IOSOB et al., 2019; 
YÁÑEZ-ESPINOSA et al., 2020). Aquaporinas são proteínas das membranas que facilitam a passagem de água e pequenos solutos nas células (LOPEZ et al., 2012). Acredita-se que essas proteínas sejam a principal forma de movimento da água pelas membranas celulares nas plantas (MAUREL et al., 2015).

A toxidez do $\mathrm{Hg}$ estimula o estresse oxidativo quando atinge patamares nos quais a célula não consegue controlar, podendo resultar em diversos eventos danosos ao metabolismo celular. A oxidação das proteínas, danos à membrana plasmática $\mathrm{e}$ ao DNA, promovendo danos aos cromossomos através da quebra dessa macromolécula são algumas das consequências. A fragmentação do DNA está associada à morte celular programada (apoptose) e pode ser utilizada como um marcador molecular para apontar a perda de viabilidade da semente (KRANNER et al., 2011; ABDELGAWAD et al., 2016; VALKO et al., 2016). Na semente, o $\mathrm{Hg}$ age diretamente no embrião ou no endosperma, interagindo rapidamente com os grupamentos tióis das células (ligações $-\mathrm{SH}$ ). Essa modificação afeta 0 desenvolvimento do embrião, uma vez que seus tecidos são ricos nesse tipo de ligação (SHARMA et al., 2017; TOMESCU et al., 2017; HANDA et al., 2018; KOHLI et al., 2019; SHAHZAD et al., 2018; SOARES et al., 2019).

As plantas que se desenvolvem nos ambientes contaminados por altas concentrações de elementos traço estão suscetíveis a uma série de alterações fisiológicas e nutricionais. Clorose, estresse hídrico, alteração no balanço hormonal, diminuição da biomassa, inibição da fotossíntese e até morte (SINGH et al., 2016; CHOUDHARY et al. 2017) são algumas dessas alterações. Determinadas espécies vegetais apresentam tolerância a esses metais (SARWAR et al., 2017; SIQUEIRASILVA et al., 2019), permitindo que os imobilize em seus tecidos, sendo esse processo conhecido como bioacumulação. A partir dessa capacidade surgiu o termo fitorremediação. A Fitorremediação de solos contaminados por elementos traço vem sendo bastante estudada nos últimos anos (MAHAJAN \& KAUSHAL, 2018). Assim, para que esse mecanismo seja eficiente é indispensável selecionar espécies que tolerem tais condições do solo (RIOS et al., 2017). Seja para utiliza-las como fitorremediadoras ou para avaliar os possíveis impactos de determinadas atividades com relação a manutenção dos ecossistemas nativos.

Conhecida popularmente como braúna, a Melanoxylon brauna é uma espécie arbórea da família Fabaceae Caesalpinoideae. Nativa do Brasil, do bioma Mata Atlântica, ocorre principalmente nos estados de Minas Gerais, São Paulo, Bahia, Rio 
de Janeiro e Espírito Santo. Possui alto valor econômico, com madeira pesada e compacta, bastante utilizada em obras externas e hidráulicas, moirões, postes, construção civil e instrumentos musicais (LORENZI, 2014). Devido à exploração e à deficiência de replantios, essa espécie está apontada como "Vulnerável" na Lista Oficial de Flora Ameaçada em Extinção (IBAMA, 2019).

A região natural da braúna, além das contaminações do solo provenientes agricultura, sofreu grandes desastres ambientais ocasionados pela atividade mineradora, principalmente no estado de Minas Gerais. Esses eventos liberaram no solo altos teores de elementos traço, potencialmente nocivos, reforçando a necessidade de pesquisas com potenciais formas de mitigar este problema, para recuperar áreas afetadas (ANA, 2016; HATJE et al., 2017; SILVEIRA et al., 2019).

Tendo em vista os relatos a respeito da toxicidade do mercúrio (CLEMENS \& MA, 2016; AZZAM et al., 2016) e a importância ecológica e econômica da espécie florestal em questão, sugere-se que o mercúrio interfere na germinação de sementes de Melanoxylon brauna, o que pode dificultar a propagação natural dessa espécie e afetar o bioma. 


\section{REVISÃO DE LITERATURA}

\subsection{Contaminação do Meio Ambiente por Elementos Traço}

A poluição do meio ambiente está diretamente associada às atividades resultantes da intervenção humana e ao rápido crescimento industrial. Atividades como a agricultura e a mineração podem eliminar parcial ou totalmente a cobertura vegetal do solo. Dessa forma, podem favorecer a sua degradação e processos de erosão, contaminação de cursos d'água e carreamento de poluentes, podendo comprometer todo o ecossistema (CAl et al., 2017; JIANG et al., 2018).

A contaminação do solo por elementos traço é considerada um problema ambiental de preocupação mundial, sendo alguns desses metais altamente prejudiciais não apenas ao meio ambiente, mas também à saúde humana (LI et al., 2014; SHAHID et al., 2017; CHEN et al., 2018).

No entanto, verifica-se naturalmente a ocorrência de elementos traço nos solos, alguns desses, como o zinco, o cobre e o ferro são essenciais para a nutrição dos animais e das plantas. Porém outros, como arsênio, chumbo, cádmio e mercúrio, são prejudiciais a diversos componentes da biosfera (CHEN et al. 2015; CLEMENS \& MA, 2016; PAN et al. 2016). Em parte das situações, tais elementos são encontrados nos solos em formas ou concentrações que não apresentam riscos ao ambiente. No entanto, nos últimos anos, pressões decorrentes das atividades antrópicas elevaram notadamente as quantidades desses metais em diversos ecossistemas (SHAHZAD et al., 2018).

O acúmulo de elementos traço próximo aos solos agrícolas representa um risco delicado à segurança ambiental. Esses compostos podem pronunciar sua capacidade poluente pontualmente nos organismos no solo, pela disposição às plantas em graus tóxicos. Além da probabilidade de serem transferidos para a cadeia alimentar, pela vegetação ou pela água (WANG et al., 2019; YUAN et al., 2019).

Periodicamente, a Agência para Substâncias Tóxicas e Registro de Doenças (Agency for Toxic Substances and Disease Registry - ATSDR - Estados Unidos) divulga uma relação de substâncias baseada na periodicidade de ocorrência, toxidez e capacidade de exposição ao ser humano. Tal lista tem como líderes o As, o $\mathrm{Pb}$ e o $\mathrm{Hg}$, entre outros, considerados altamente prejudiciais à saúde humana (ATSDR, 2017). 
A alta capacidade de poluição dos solos por elementos traço está associada à alta toxicidade, persistência e acúmulo destes elementos no solo (ALI, MALIK, SHINWARI \& QADIR, 2015; JIANG et al., 2017). Esses compostos não são biodegradados e são transferidos para os níveis tróficos superiores da cadeia alimentar, sendo acumulados ao longo da biota (REZANIA et al., 2016).

Diversos fatores controlam a absorção dos elementos traço pelas raízes das plantas, como a quantidade desses elementos disponível no meio, o pH, a matéria orgânica e a capacidade de troca catiônica do solo. Dentre os fatores relacionados à planta estão o tipo de cultura e fertilizantes adotados, o estágio de desenvolvimento dessa, entre outros (LENTE et al., 2014; YADAV et al., 2018).

Tem-se conhecimento de que em ambientes com altas concentrações desses elementos, as plantas podem apresentar diversas anomalias nutricionais e fisiológicas. Dentre elas a inibição da etapa germinativa, alterações nas taxas fotossintéticas, clorose foliar devido a degradação da clorofila, diminuição da biomassa e alteração nos balanços hídrico e hormonal (AHMAD et al., 2016; ANJUM et al. 2016, ALVES et al., 2017). Alguns dados da Companhia Ambiental do Estado de São Paulo (CETESB, 2017) relatam que até o ano de 2017, existiam em torno de 5.942 áreas contaminadas por esses tipos de metais, registradas apenas no território do Estado de São Paulo.

\subsection{Elementos Traço}

Os elementos traço também são conhecidos por outras denominações, como metais pesados, metais traço e microelementos (HOODA, 2010; SHANG et al., 2019). Eles consistem em, aproximadamente, sessenta e cinco elementos metálicos, com densidade superior a $5 \mathrm{~g} \mathrm{~cm}^{-3}$ (Ll et al., 2014). Tais elementos podem estar associados ou não a outros elementos químicos, dando origem a diferentes compostos (HU et al., 2013; CHEN et al., 2015).

Como já citado, alguns desses elementos são essenciais ao desenvolvimento dos vegetais por serem constituintes de enzimas e de proteínas, como o zinco. Entretanto, esses se tornam tóxicos quando excedem suas concentrações ideais aos organismos. Já outros elementos mencionados não exercem funções conhecidas no metabolismo dos vegetais e são tóxicos em concentrações mínimas (RODRIGUES et al., 2016). 
Nas sementes, de um modo geral, os elementos traço influenciam a germinação de duas formas principalmente, através da inibição da absorção da água, regulando o funcionamento das aquaporinas (AQPs), e por sua toxidez, que leva ao estresse oxidativo (KRANNER et al., 2011; CARDOSO et al. ,2015; WANG et al., 2016; EL RASAFI et al., 2016). Alguns experimentos indicaram que essa interferência pode variar com a concentração do metal, podendo não mostrar efeito significativo, quando em baixas concentrações (KRANNER e COLVILLE, 2011; SADERI e ZARINKAMAR, 2012).

A respeito do $\mathrm{Hg}$, alguns pesquisadores relataram que esse pode ser responsável por inibir a atividade das AQPs em sementes (WILLIGEN et al., 2006; CARDOSO et al., 2015), e em suas partes, como no eixo embrionário (OBROUCHEVA et al., 2012; NOVIKOVA et al., 2014). As aquaporinas são proteínas encontradas nas membranas que facilitam a passagem de água na célula por meio da formação de um canal (PARK et al., 2010). O bloqueio da atividade dessas proteínas, na maioria dos casos pode ser um processo reversível, devido à ação de agentes redutores, como o DTT (ditiotreitol) e o 2BME (2-mercaptoetanol). Esses compostos proporcionam às aquaporinas condições para que retornem à sua configuração original (JAIN et al., 2008). Essa prática já foi utilizada em experimentos com sementes de Aesculus hippocastanum (OBROUCHEVA et al., 2012), Plathymenia reticulata (CARDOSO et al., 2015), e em eixos embrionários de Vicia faba (NOVIKOVA et al., 2014)

\subsection{A Toxidez do Mercúrio e Estresse Oxidativo nas Plantas}

O Mercúrio $(\mathrm{Hg})$ é apontado como um elemento extremamente tóxico, não somente às plantas, mas também aos animais e aos seres humanos. Pode ser encontrado no solo, na água e na atmosfera (CLEMENS \& MA, 2016; AZZAM et al., 2016). Sua toxicidade é variável nos seus diferentes compostos, sendo a forma orgânica altamente tóxica para toda a biota, podendo se acumular ao longo da cadeia alimentar (PAN et al., 2016).

Pode ser produto tanto de atividades humanas (agrotóxicos), quanto de eventos naturais (ZHOU et al., 2007). Além da sua forma metálica, pode ser encontrado como composto bioativo e sal, ambos solúveis em água (o que gera efeito ainda mais tóxico). Esse metal, quando presente no solo, pode agir diretamente no embrião da semente ou no endosperma, atuando nas ligações -SH (grupamentos tióis das células), formando ligações -S-Hg-S-. Tal modificação na conformação molecular 
afeta o desenvolvimento do embrião, visto que esses tecidos possuem muitas dessas ligações-SH (TOMESCU et al. 2017; SHARMA et al. 2017, 2018; SOARES et al. 2019).

$\mathrm{O} \mathrm{Hg}$ ainda tem a capacidade de interagir com grupos sulfidrilas de enzimas e outras proteínas radiculares das plantas, obstruindo a passagem de água e comprometendo a integridade da membrana (RASCIO \& NAVARI-IZZO, 2011). Na semente, o aumento na quantidade de cloreto de mercúrio leva à redução da taxa de respiração, dos níveis de nitrogênio, RNA, DNA e açúcar nos embriões (NAG et al., 1989).

Por comprometer diversos processos celulares, a toxicidade do mercúrio pode interagir com enzimas compostas por grupamentos tióis, marcando o estado redox celular (AHMAD et al., 2012). Dessa forma conduzindo ao estresse oxidativo nos tecidos vegetais (ZHANG et al., 2007), que causa inibição do crescimento das plantas (JUKNYS et al., 2012).

O estresse oxidativo é causado por radicais livres e átomos de oxigênio capazes de reagir facilmente devido seu balanço de elétrons, conhecidos como "espécies reativas de oxigênio" (EROs), que, em excesso, causam danos aos compostos celulares (GAJEWSKA e SLODOWSKA, 2008; AHMAD et al., 2010; GILL e TUTEJA, 2010; SHARMA et al. 2012; DEMIDCHIK, 2015). Todavia, o processo de oxidação é essencial ao metabolismo aeróbico e, em consequência disso, algumas EROs são produzidas naturalmente, como a hidroxila e o ânion superóxido (BARREIROS et al., 2006). Entretanto, quando condições de estresse aumentam, pode ocorrer a superprodução desses agentes oxidantes. Assim, possibilita o seu acúmulo e as células são levadas ao estresse oxidativo (AHMAD et al., 2010; GILL e TUTEJA, 2010; HONG et al, 2015).

Em geral, os efeitos toxicológicos dos elementos traço nas plantas estão relacionados a condições de estresse (MITHOFER et al., 2004; KOIVULA e EEVA, 2010). Visando o combate da oxidação celular, os vegetais desenvolveram mecanismos de defesa, a partir de meios enzimáticos ou não (GILL e TUTEJA, 2010; PATEL et al., 2016).

\subsection{A Importância dos Estudos sobre Germinação e Substratos}

Os substratos onde as sementes se encontram é um fator decisivo na germinação e no crescimento inicial das plântulas (BARON et al., 2011). Suas 
características físicas e químicas são muito importantes para que uma espécie tenha sucesso germinativo, como a estrutura do solo, o pH, a capacidade de retenção de água, o grau de contaminação por patógenos e a disponibilidade de nutrientes no meio (SILVA et al., 2014).

A germinação engloba os processos iniciais do desenvolvimento da planta. Os acontecimentos fisiológicos envolvidos na germinação têm início com a embebição das sementes (FLORES, 2011; BEWLEY, 2013). A água estimula a ativação e/ou a síntese de enzimas e proteínas, impulsionando a mobilização de reservas, enfraquecendo a parede celular. Portanto, faz com que o tegumento se rompa pela força exercida pela pressão da raiz primária. Assim sendo, é imprescindível conhecer sobre as condições adequadas que possibilitem a germinação e o bom crescimento das plântulas (CARVALHO \& NAKAGAWA, 2012; NOGUEIRA et al., 2012).

Conhecer a germinação das sementes é necessário para averiguar a influência das variáveis ambientais nesse processo, analisar as técnicas de superação de dormência e inspecionar os efeitos do processamento e do armazenamento das sementes (GORDIN et al., 2012). Durante a germinação das sementes, características como a uniformidade e a rapidez são almejáveis, pois sementes no estágio de germinação são altamente sensíveis (BOTELHO et al., 2008) A utilização de sementes com alto vigor possui vantagens como germinação rápida e homogênea, aquisição de plântulas tolerantes a adversidades ambientais e maturação mais uniforme. Esses fatores podem gerar maior sobrevivência, e estabelecimento de plântulas (NERLING, 2013).

Algumas espécies são capazes de sobreviver e crescer em ambientes contaminados por elementos considerados tóxicos (GUPTA, 2013). Essa sobrevivência está relacionada ao potencial de tolerar a toxicidade dos elementos contaminantes, e não de anulá-la. Nas últimas décadas, muitos têm sido os esforços que visem à recuperação e melhora dos solos poluídos por elementos traço, sendo uma das alternativas estudadas, o emprego dessas plantas tolerantes e bioacumuladoras. Esse procedimento é denominado como Fitorremediação (GREIPSSON, 2011). Todavia, para que se obtenha êxito nesse processo, é preciso ter conhecimento da capacidade tóxica dos poluentes nas espécies vegetais, para, posteriormente, introduzi-las nas áreas contaminadas (REZANIA, 2016). A fitorremediação apresenta vantagens como baixo custo de implantação, impacto ambiental reduzido, fácil implementação e manejo das espécies utilizadas, 
melhoramento visual do ambiente a receber o tratamento e reciclagem dos materiais empregados (DE SOUZA, KONRAD, GONÇALVEZ JUNIOR, 2017; UEBEL et al., 2017).

\subsection{A espécie: Melanoxylon brauna}

Melanoxylon brauna Schott., é uma espécie nativa do bioma Mata Atlântica, pertencente à família Fabaceae e subfamília Caesalpinioideae, classificada como uma espécie arbórea secundária inicial, semidecídua e heliófila (SANTOS et al. 2004). Popularmente é chamada de braúna, baraúna, braúna-preta, rabo-de-macaco, graúna e maria-preta. Ocorre no Brasil nos estados de Minas Gerais, Espírito Santo, Rio de Janeiro, Bahia, São Paulo e Pará.

Suas árvores compreendem de 15 a 25 metros de altura e diâmetro de 40 a 80 centímetros, as flores são de coloração amarelada e os frutos são deiscentes, sendo a dispersão das sementes feita pelo vento (LORENZI, 2014).

A madeira de Melanoxylon brauna possui alta densidade $\left(1,05 \mathrm{~g} \mathrm{~cm}^{-3}\right) \mathrm{e}$ elevada durabilidade, é compacta e apresenta grande rigidez ao corte. Por essas características, pode ser utilizada em obras externas e hidráulicas, como na indústria de navegação, de postes de iluminação e mourões de cercas, além de ser amplamente difundida na indústria moveleira. É considerada uma espécie potencial para arborização urbana e plantios de reflorestamentos (LORENZI, 2014).

Durante anos, foi explorada sem manejo adequado, um dos motivos que levou à drástica perda na abundância e redução da variabilidade genética dessa espécie. Com sua acentuada exploração e a escassez de replantios, a braúna foi classificada como "Vulnerável" na "Lista Oficial de Flora Ameaçada em Extinção" (IBAMA, 2019). Logo, essa é considerada uma espécie de conservação prioritária (CREPALDI; PEIXOTO, 2010).

Usualmente, a propagação de braúna é feita por meio de sementes (BORGES et al., 2015), e sua germinação já é bastante estudada (FLORES et al., 2013; FLORES et al., 2014; LIMA E BORGES et al., 2015; LIMA E BORGES; ATAÍDE; MATOS, 2015; ATAÍDE; LIMA E BORGES; LEITE FILHO, 2016; ATAÍDE et al., 2017; SANTOS et al., 2017). Entretanto, há poucas informações na literatura relacionadas a sua germinação em condições de estresse, como por contaminação por elementos traço. Tal fato corrobora os objetivos desse estudo, visto que algumas áreas de ocorrência natural dessa espécie têm sofrido muito com contaminações de origem antrópica nas últimas 
décadas. Como o estado de Minas Gerais, que devido ao seu histórico de intensa exploração do ouro, ocorrida durante século XIX, apresenta diversas regiões de contaminação por Hg (TINÔCO et al., 2010). 


\section{OBJETIVOS}

\subsection{Geral}

Investigar os efeitos do mercúrio na germinação e no metabolismo de sementes de Melanoxylon brauna.

\subsection{Específicos}

Estabelecer a relação entre a presença do mercúrio e o crescimento dos embriões das sementes;

Avaliar se a variação da concentração de $\mathrm{Hg}$ afeta a germinação, atrasando o processo ou causando a morte da semente.

Verificar a interferência do $\mathrm{Hg}$ na anatomia e na mobilização de reservas durante a germinação;

Avaliar as atividades das enzimas $\alpha$-amilase e $\beta$-amilase nas sementes submetidas ao $\mathrm{HgCl}_{2}$.

Avaliar as possíveis alterações bioquímicas na peroxidação de lipídeos e nas taxas respiratórias das sementes de braúna submetidas ao Hg; 


\section{MATERIAL E MÉTODOS}

\subsection{Coleta de Sementes}

Os frutos de Melanoxylon brauna foram colhidas de, pelo menos, cinco árvores na região de Leopoldina, no ano de 2019 e levadas ao Laboratório de Análise de Sementes Florestais do Departamento de Engenharia Florestal da Universidade Federal de Viçosa. Após secagem ao sol, as sementes foram beneficiadas e homogeneizadas, compondo um único lote. As sementes foram armazenadas em geladeira (aproximadamente $5 \stackrel{\circ}{\circ}$ ), em sacos plásticos.

\subsection{Teste de Germinação e IVG das Sementes}

As sementes foram selecionadas e tratadas com fungicida CAPTAN a $0,2 \%$ por três minutos. Em seguida, foram distribuídas em placas de petri previamente esterilizadas com álcool etílico 70\%, forradas com duas folhas de papel germitest e umedecidas com água destilada (cinco placas, contendo vinte sementes cada). teste de germinação foi realizado na temperatura de $25^{\circ} \mathrm{C} \pm 5$, sob luz constante proporcionada por quatro lâmpadas de $40 \mathrm{~W}$. O monitoramento da germinação foi realizado diariamente, pelo período de dez dias, sendo consideradas sementes germinadas aquelas que apresentaram protrusão da raiz primária (Tabela 1). As informações obtidas foram utilizadas para calcular a porcentagem de germinação e o índice de velocidade de germinação, segundo Maguire (1962).

\subsection{Testes de Concentrações das Soluções de Mercúrio}

Os tratamentos consistiram em soluções de cloreto de mercúrio $\left(\mathrm{HgCl}_{2}\right)$ e tratamento controle (somente água). Primeiramente, foram usadas soluções com diluições de $25,50,75,100 \mu \mathrm{M}$ e $1 \mathrm{mM}$ de $\mathrm{HgCl}_{2}$. No entanto, observou-se pouco efeito desses sobre a germinação. Posteriormente, foram testadas soluções com concentrações mais elevadas de $\mathrm{HgCl}_{2}(1,2,3,4$ e $5 \mathrm{mM})$, com o objetivo de estabelecer concentrações que fornecessem resultados significativos $(p>0,05)$ na porcentagem de germinação das sementes.

\subsection{Desponte e Vácuo nas Sementes}

As sementes foram seccionadas com tesoura no lado contrário ao eixo embrionário. Em testes preliminares observou-se dificuldade de penetração das 
soluções no interior da semente. Em seguida, as sementes seccionadas foram imersas nas soluções com as concentrações de $\mathrm{Hg}$ sob vácuo por 30min e mantidas nas soluções por mais 20min, sem vácuo.

\subsection{Expansão Longitudinal}

Essa etapa do estudo foi feita para medir a variação da expansão longitudinal dos eixos embrionários das sementes nas concentrações de $\mathrm{Hg}$ estabelecidas (nessa etapa, utilizou-se água e soluções de $\mathrm{HgCl}_{2}$ a $1 \mathrm{mM}, 3 \mathrm{mM}$ e $5 \mathrm{mM}$ ).

Os embriões foram extraídos com o auxílio de alicate, estilete e pinça. As dimensões $(\mathrm{mm})$ dos eixos embrionários foram mensuradas por meio de imagens escalonadas registradas por câmera digital e processadas com o auxílio do software Image Pro Plus 4.5.0.29 (Tabela 2).

\subsection{Teste de Embebição e Curva de Hidratação}

Para avaliar o teor de água (TA) dos embriões, estudar sua absorção pelas sementes expostas ao mercúrio e determinar as curvas de hidratação, os embriões foram pesados e submetidos a secagem, após 0, 1, 2, 3 e 4 dias de embebição. O TA foi determinado pelo método de secagem em estufa a $105^{\circ} \mathrm{C}$, por 2 horas, utilizando, para cada tratamento, três repetições com 10 embriões em cada. A pesagem foi realizada em balança de precisão a $0,001 \mathrm{~g}$. O resultado foi expresso em porcentagem de umidade (base seca), calculada pela Equação 1:

$$
U \%=\left(\frac{\text { Massa úmida }- \text { Massa seca }}{\text { Massa seca }}\right) \times 100
$$

\subsection{Análise Anatômica}

As sementes foram incubadas nos diferentes tratamentos: controle (água), $1 \mathrm{mM}, 3 \mathrm{Mm}$ e $5 \mathrm{mM} \mathrm{HgCl}_{2}$ por 0, 48 e 96 horas. Em seguida, foram fixadas em FAA50 (formaldeído, ácido acético, etanol 50\% - 1: 1: 18 - v: v), por 48h sob vácuo e posteriormente armazenados em etanol 70\% (Johansen, 1940). Posteriormente, o material vegetal foi desidratado em série etanólica $(70,85,95 \%)$ e colocadas em resina pura e álcool $95 \%$ (1:1), por 7 dias. Após este procedimento transferidas para resina pura por 30 dias. Por fim, incluídas em metacrilato (Historesina-Leica), de acordo com as recomendações do fabricante. As amostras foram seccionadas com $5 \mu \mathrm{m}$ de espessura em um micrótomo rotativo avançado automático (modelo RM2155, 
Leica microsystems Inc., Deerfield, EUA). As secções longitudinais foram coradas com azul de toluidina em tampão acetato, $\mathrm{pH} 4,7$. Em seguida lâminas permanentes foram montadas com resina sintética (Permount ${ }^{\circledR}$ ) (O’BRIEN et al., 1981). Essas amostras foram fotografadas com um microscópio de luz (modelo AX-70 TRF, Olympus Optical, Tóquio, Japão), acoplado a uma câmera digital (Zeiss AxioCam modelo HRc, Göttinger, Alemanha).

\subsection{Mobilização de Reservas}

Foram retiradas amostras de embriões de cada tratamento nos tempos de zero, 48 e 96 horas, acondicionadas em vidros hermeticamente fechados e mantidas a -20 ${ }^{\circ} \mathrm{C}$ até a extração e quantificação das reservas.

Para extrair os lipídeos, utilizou-se amostras de eixos embrionários e cotilédones secos a $45^{\circ} \mathrm{C}$ por 24 horas e triturados. Em seguida, foram colocadas em cartuchos de papel-filtro, pesadas e transferidas para conjunto extrator sohxlet por um período de 24 horas, sendo a extração realizada a frio, com éter de petróleo (SILVA, 1990). Foram realizadas três repetições para cada amostra retirada. Após esta etapa, os cartuchos foram secos em estufa ( $45^{\circ} \mathrm{C}$ por 24 horas) e pesados novamente. $\mathrm{O}$ teor de lipídeos foi calculado através da diferença de massa entre as amostras antes e após o processo de extração.

Para extração dos açúcares solúveis foi utilizada a metodologia descrita por Buckeridge e Dietrich (1990), com modificações. Quatro amostras de $100 \mathrm{mg}$ de material desengordurado foram mantidas em álcool 80\%, em banho-maria, a $75 \stackrel{\circ}{\circ}$, durante 30 minutos, e centrifugadas a 10.000 x g durante 5 minutos, para a coleta do sobrenadante. Esse processo foi repetido por mais três vezes. Após as extrações as amostras foram levadas à estufa por 24 horas, a $45^{\circ} \mathrm{C}$ e, em seguida, ressuspendidas com 1,0 mL de água destilada, que foi utilizada para as análises de açúcares solúveis totais. A quantificação foi realizada a partir da diluição de $5 \mu \mathrm{L}$ da amostra, pelo método colorimétrico fenolsulfúrico (DUBOIS et al., 1956).

Os precipitados das amostras da extração dos açúcares solúveis, após secos em estufa, foram utilizados para extração e quantificação do amido. Foram utilizadas quatro amostras de $20 \mathrm{mg}$, submetidas à digestão com 1,0 mL de ácido perclórico $35 \%$, durante 15 minutos. Após a digestão as amostras foram centrifugadas a 10.000 x g, durante 5 minutos (PASSOS, 1996). A quantificação do amido foi realizada em 
alíquotas de $5 \mu \mathrm{L}$ do sobrenadante, pelo método colorimétrico, conforme metodologia descrita por Dubois et al. (1956).

A extração das proteínas solúveis nos cotilédones foi feita utilizando o tampão TRIS-HCl, conforme Alfenas (1991). Após incubação a $25^{\circ} \mathrm{C}$, durante 30 minutos, as amostras foram centrifugadas a $3000 \times$ g durante 20 minutos. O sobrenadante foi, então, coletado e o precipitado ressuspendido, repetindo-se por mais duas vezes a incubação, centrifugação e coleta do sobrenadante. A quantificação das proteínas solúveis foi determinada através do método de Bradford (1976), utilizando o reagente Comassie Blue G-250. As leituras foram feitas em espectrofotômetro a 595nm e comparadas com a curva de referência obtida com concentrações conhecidas de soro-albumina bovina - BSA.

\subsection{Atividade das Enzimas $\alpha$-amilase e $\beta$-amilase}

A atividade da $\alpha$-amilase foi determinada com $250 \mu \mathrm{L}$ do extrato obtido adicionado a $150 \mu \mathrm{L}$ de $\mathrm{CaCl}_{2} 3 \mathrm{mM}$, para inativação da $\beta$-amilase, incubado a $70{ }^{\circ} \mathrm{C}$ por 5 minutos. À essa alíquota foram adicionados a $250 \mu \mathrm{L}$ de tampão citrato de sódio 100 mM, pH 5,0 e $125 \mu \mathrm{L}$ de solução de amido a 1\%, incubados por 5 minutos, a 30 ${ }^{\circ} \mathrm{C}$. A reação foi interrompida pela adição de $500 \mu \mathrm{L}$ do ácido 3,5-dinitrosalicílico 1\% (DNS). Em seguida, o conteúdo foi fervido por 10 minutos e transferido para uma proveta, completando-se o volume para $2500 \mu \mathrm{L}$ (TÁRRAGO e NICOLÁS, 1976; KISHOREKUMAR et al., 2007).

A determinação da atividade da enzima $\beta$-amilase foi iniciada pela adição de $250 \mu \mathrm{L}$ de extrato enzimático ao meio de reação contendo $150 \mu \mathrm{L}$ de EDTA 0,1 M, para inativação de $\alpha$-amilase. À alíquota foram adicionados $250 \mu \mathrm{L}$ de tampão citrato de sódio $100 \mathrm{mM}, \mathrm{pH} 3,4$ e $125 \mu \mathrm{L}$ de solução de amido a $1 \%$, incubados a $30{ }^{\circ} \mathrm{C}$ por 5 minutos. Feito isso, adicionou-se $500 \mu \mathrm{L}$ de DNS 1\%, aqueceu-se por 10 minutos e, em seguida, transferiu-se o conteúdo para uma proveta, completando-se o volume para $2500 \mu \mathrm{L}$. Os açúcares redutores formados pela ação da $\alpha$ e $\beta$-amilase foram quantificados pela leitura da absorbância em $540 \mathrm{~nm}$ e os cálculos foram realizados utilizando a curva padrão de maltose $0,5 \mathrm{mg} \mathrm{mL}^{-1}$ (TÁRRAGO e NICOLÁS, 1976; KISHOREKUMAR et al., 2007).

\subsection{Determinação da Concentração de Malonaldeído}


A determinação da concentração de malonaldeído (MDA) foi realizada em amostras contendo $200 \mathrm{mg}$ de embriões. A maceração das amostras foi realizada com $2 \mathrm{~mL}$ de TCA $1 \%(\mathrm{p} / \mathrm{v})$ seguida da centrifugação a $12000 \times \mathrm{g}$, por 4 minutos. Uma alíquota de $500 \mu \mathrm{L}$ do sobrenadante foi adicionado a $1,5 \mathrm{~mL}$ de TBA $0,5 \%(\mathrm{p} / \mathrm{v})$, em TCA $20 \%$. A mistura foi incubada em água a $90{ }^{\circ} \mathrm{C}$ por 20 minutos e a reação foi paralisada em banho de gelo por um minuto. Em seguida, as amostras foram centrifugadas a $3000 \times \mathrm{g}$ durante $4 \mathrm{~min}$. A leitura da absorbância foi realizada a 440 $\mathrm{nm}, 532 \mathrm{~nm}$ e $600 \mathrm{~nm}$. Foi utilizado o coeficiente de absortividade molar de 155 $\mathrm{mM}^{-1} \mathrm{~cm}^{-1}$ para quantificar a concentração dos peróxidos de lipídeos, sendo os resultados expressos em nmol. $\mathrm{ml}^{-1}$ (DU \& BRAMLAGE, 1992).

\subsection{Análise da Atividade Respiratória e Verificação da Morte Celular} Programada.

A atividade respiratória foi analisada através do consumo de oxigênio em câmara de reação fechada, com agitação constante, a $25^{\circ} \mathrm{C}$, com a capacidade de $1,0 \mathrm{~mL}$, por 10 minutos. O consumo de oxigênio foi avaliado com eletrodo tipo Clark (ESTABROOK et al., 1967). O índice de controle respiratório foi avaliado pela razão entre a velocidade de consumo de oxigênio, por minuto, por massa fresca de semente CHANCE e WILLIANS, 1956). Os resultados foram expressos em nmol O $\mathrm{g}^{-1} \mathrm{~min}^{-1}$. Nessa avaliação foram analisadas 5 repetições contendo 10 sementes cada. As sementes foram incubadas nos tratamentos controle e $\mathrm{HgCl}_{2} 5 \mathrm{mM}$, a $25^{\circ} \mathrm{C}$, por 0,48 e 96 horas. A mesma quantidade de sementes foi utilizada para verificação de morte celular programada através da submersão das sementes, sem o tegumento, em solução de azul de Evans 1\%.

\subsection{Delineamento Experimental e Análises Estatísticas}

Para os testes realizados, o delineamento estatístico utilizado foi o inteiramente casualizado com cinco repetições, contendo 20 sementes cada. Os dados foram submetidos à análise de variância (ANOVA), e as médias comparadas pelo teste Tukey $(P<0,5)$, utilizando o software $R$. Os gráficos foram confeccionados com auxílio do software Sigmaplot 11.0. 


\section{RESULTADOS}

A porcentagem média de germinação do controle foi de 76\%. A germinação nas diluições de $25,50,75,100 \mu \mathrm{M}$ e $1 \mathrm{mM}$ de $\mathrm{HgCl}_{2}$ e do controle não diferiram significativamente entre si $(p<0,05)$ (Figura 1).

Figura 1: Porcentagens de germinação das sementes de Melanoxylon brauna no tratamento controle e nas concentrações iniciais de $\mathrm{HgCl}_{2}$; ${ }^{*}$ Médias seguidas de mesma letra não diferem entre si pelo teste de Tukey, $(P<0,05)$.

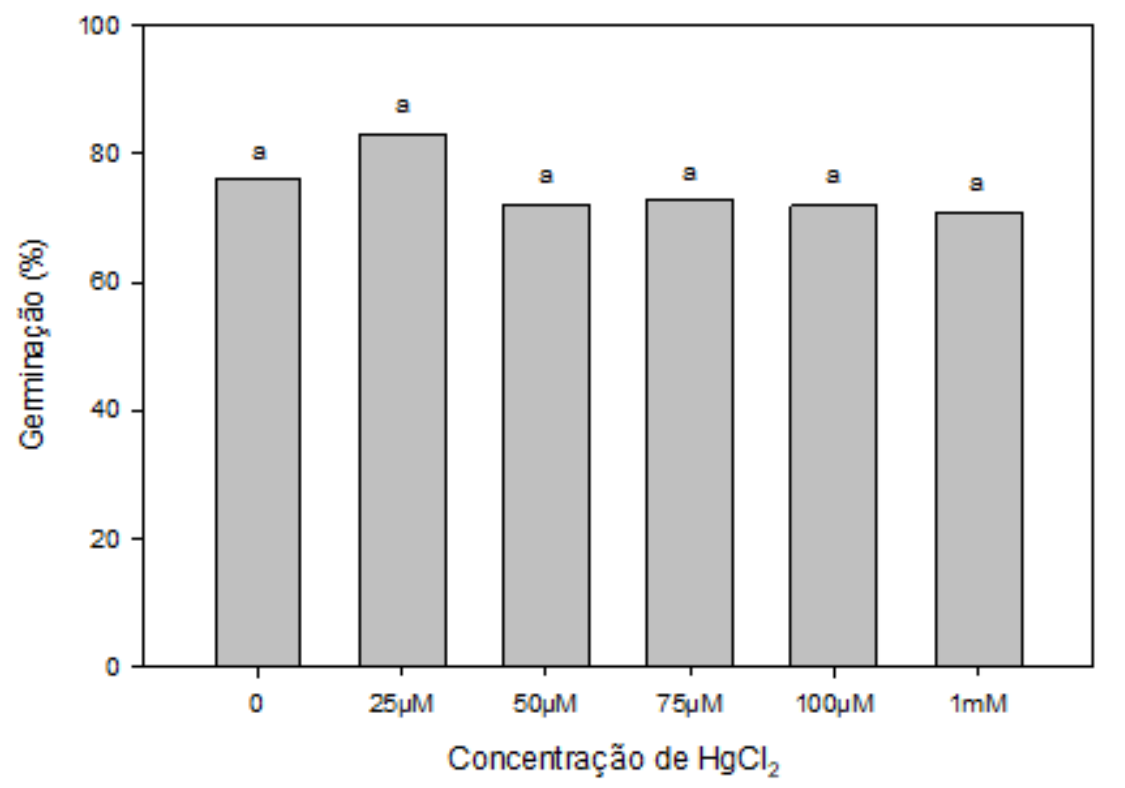

Fonte: Autora, 2020.

As sementes tratadas com concentrações mais baixas de $\mathrm{HgCl}_{2}(25,50,75$, $100 \mu \mathrm{M}$ e $1 \mathrm{mM}$ ) apresentaram valores de IVG semelhantes (Figura 2). 
Figura 2: Efeito das concentrações iniciais de $\mathrm{HgCl}_{2}$ (0: água; $25,50,75,100 \mu \mathrm{M}$ e $1 \mathrm{mM}$ ) no Índice de Velocidade de Germinação (IVG) das sementes de Melanoxylon brauna; *Médias seguidas de mesma letra, não diferem entre si pelo teste de Tukey, $(P<0,05)$.

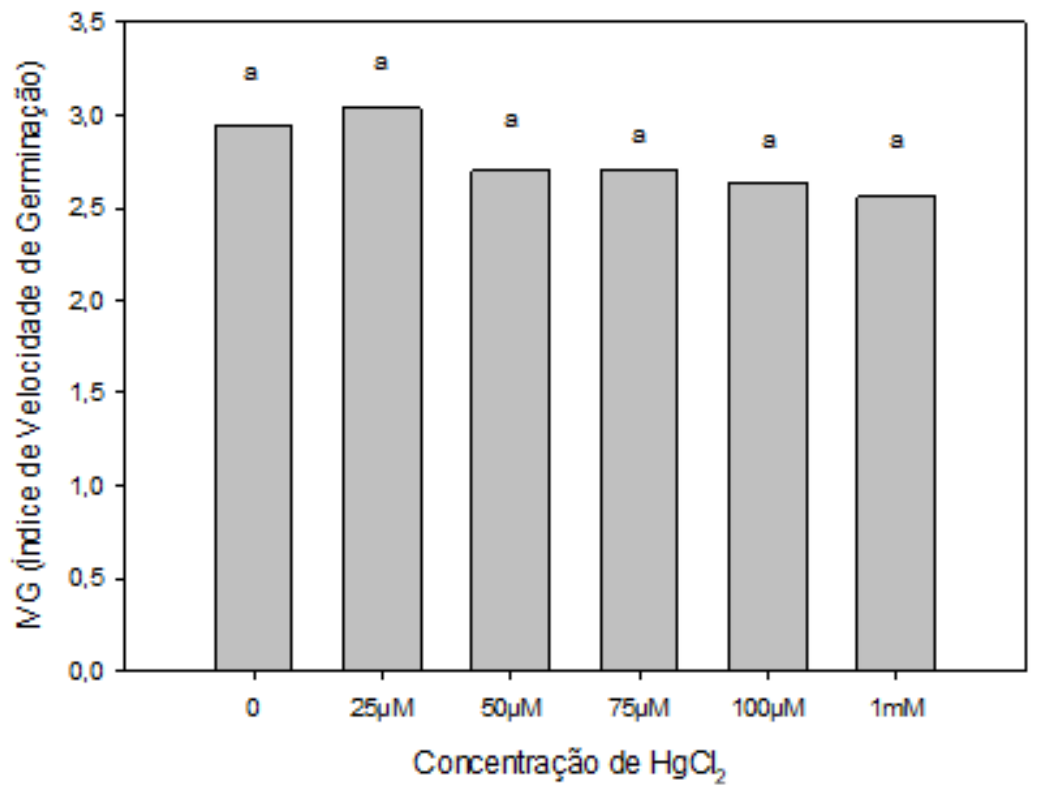

Fonte: Autora, 2020.

No segundo teste a porcentagem de germinação decresceu progressivamente de 76\% (controle) para 50\% (5mM) (Figura 3). O IVG das sementes submetidas ao tratamento controle diferiu significativamente dos demais tratamentos (Figura 4). As sementes tratadas com concentrações de 2, 3 e $4 \mathrm{mM}$ foram estatisticamente semelhantes entre si e diferiram significativamente das demais. O menor valor de IVG foi observado nas sementes submetidas à solução de concentração mais elevada ( $\mathrm{HgCl}_{2}$ a $\left.5 \mathrm{mM}\right)$. Esses resultados indicam que o vigor das sementes é afetado negativamente à medida que se aumenta a concentração de mercúrio na solução. 
Figura 3: Porcentagens de germinação das sementes de Melanoxylon brauna em maiores concentrações de $\mathrm{HgCl}_{2}$; "Médias seguidas de mesma letra, não diferem entre si pelo teste de Tukey, $(\mathrm{P}<0,05)$.

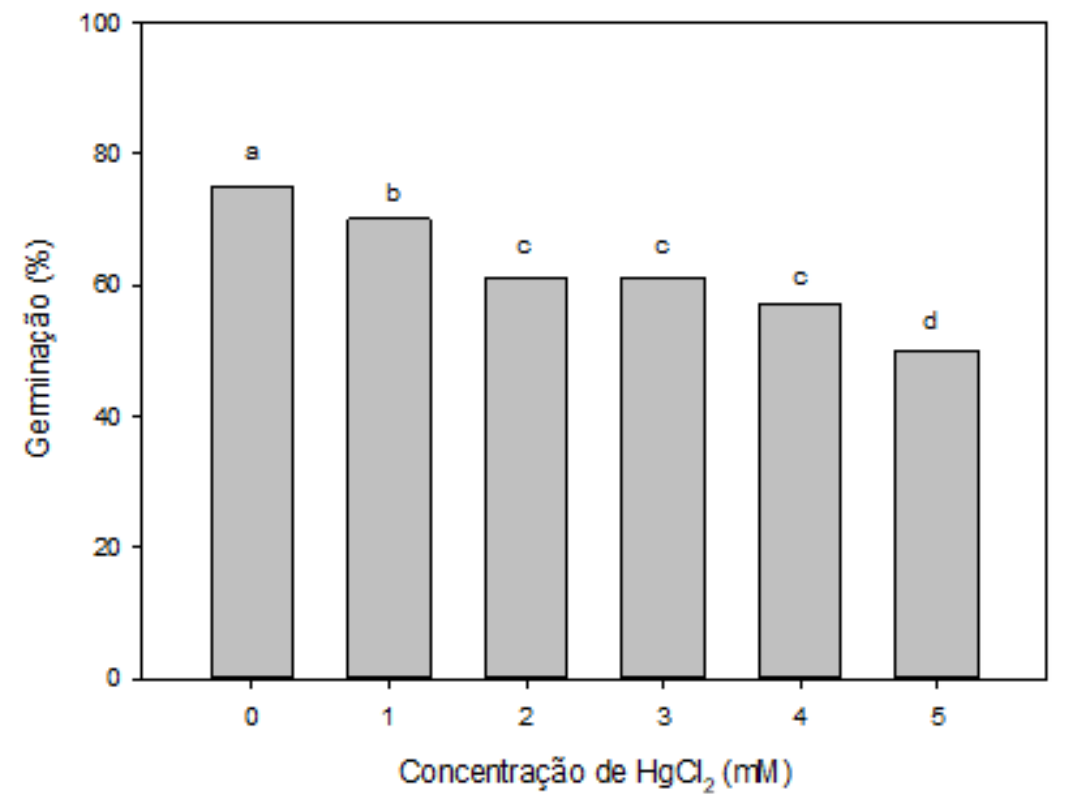

Fonte: Autora, 2020.

Figura 2: Efeito das concentrações de $\mathrm{HgCl}_{2}$ (0: água; 1,2,3,4 e $5 \mathrm{mM}$ ) no Índice de Velocidade de Germinação (IVG) das sementes de Melanoxylon brauna; *Médias seguidas de mesma letra, não diferem entre si pelo teste de Tukey, $(P<0,05)$.

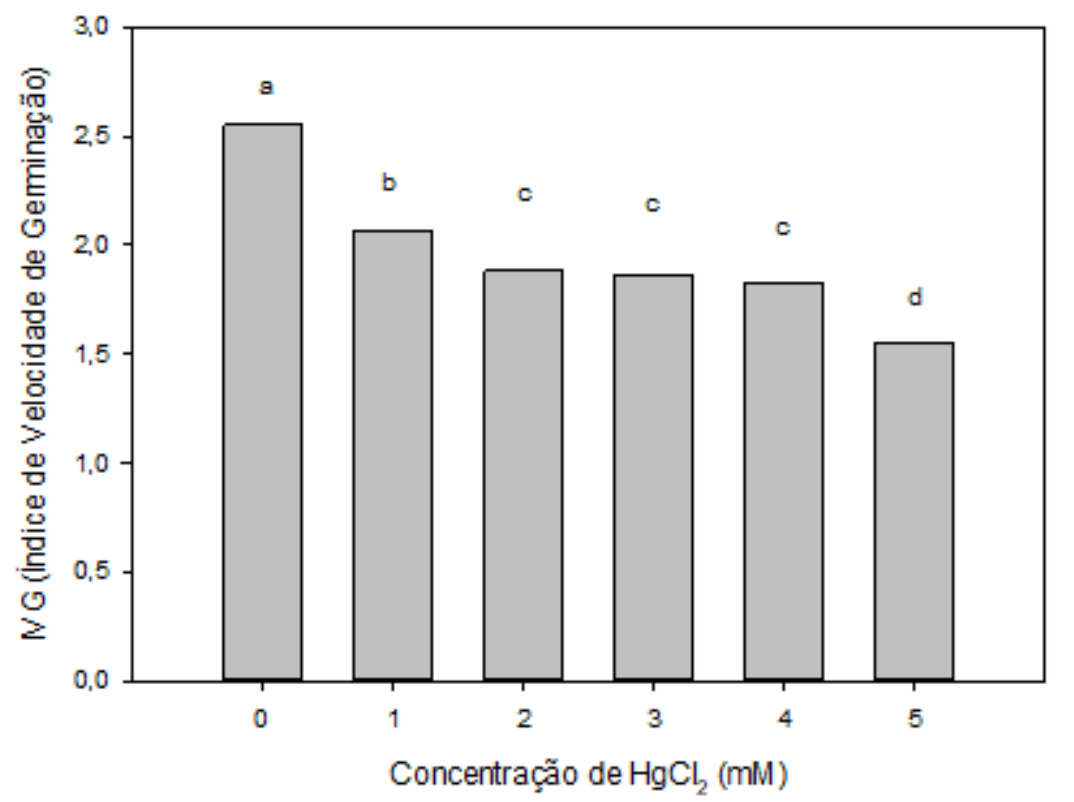

Fonte: Autora, 2020. 
Houve redução significativa no comprimento dos eixos embrionários, sendo afetados pelo aumento da concentração de mercúrio (Tabela 1). A diferença no crescimento médio entre os embriões submetidos ao tratamento controle e aos imersos em soluções de $\mathrm{HgCl}_{2}$ foi observada já no primeiro dia. Os eixos embrionários nas soluções de $\mathrm{HgCl}_{2}$ a 1 e $3 \mathrm{mM}$ cresceram 0,7 e $1 \mathrm{~mm}$ a mais em relação ao controle (água), respectivamente (Tabela 1). O crescimento médio dos eixos embrionários no tratamento controle foi consideravelmente superior (88\%), ao dos mantidos em $5 \mathrm{mM}$ de $\mathrm{HgCl}_{2}$, ao longo de todo período experimental. No último dia, o comprimento médio dos eixos embrionários do tratamento controle diferiu significativamente daqueles tratados com a solução com maior concentração de $\mathrm{Hg}$, apresentando crescimento 3,12 vezes maior que o dos eixos tratados com $5 \mathrm{mM}$ de $\mathrm{HgCl}_{2}$ (Tabela 1. A partir do dia 3 observou-se a maior diferença no crescimento médio dos embriões controle em relação aos embriões da solução de $5 \mathrm{mM}$ de $\mathrm{HgCl}_{2}$. Nesse período, os eixos embrionários tratados com água cresceram significativamente, aproximadamente, $97 \%$ a mais que os tratados com a última solução, no referido período (Tabela 1).

Tabela 1: Comprimento médio dos eixos embrionários das sementes de Melanoxylon brauna no tratamento controle e em soluções de $\mathrm{HgCl}_{2} 1 \mathrm{mM}, 3 \mathrm{mM}$ e $5 \mathrm{mM}$, nos dias $0,1,2,3$ e 4.

\begin{tabular}{ccccccc}
\hline \multirow{2}{*}{\multicolumn{2}{c}{ Tratamentos }} & \multicolumn{6}{c}{ Tempo (dia) } \\
\cline { 3 - 7 } & Água & 6 & 1 & 2 & 3 & 4 \\
\hline \multirow{2}{*}{$\begin{array}{c}\text { Comprimento } \\
(\mathrm{mm})\end{array}$} & $1 \mathrm{mM} \mathrm{HgCl}_{2}$ & $6,7 \mathrm{a}$ & $9,6 \mathrm{a}$ & $13,8 \mathrm{a}$ & $14,5 \mathrm{a}$ & $29,1 \mathrm{a}$ \\
& $3 \mathrm{mM} \mathrm{HgCl}_{2}$ & $6,7 \mathrm{a}$ & $10,6 \mathrm{a}$ & $10,5 \mathrm{~b}$ & $10,7 \mathrm{~b}$ & $11,6 \mathrm{c}$ \\
& $5 \mathrm{mM} \mathrm{HgCl}_{2}$ & $6,7 \mathrm{a}$ & $9,5 \mathrm{a}$ & $10,2 \mathrm{~b}$ & $8,9 \mathrm{~b}$ & $9,3 \mathrm{c}$ \\
\hline
\end{tabular}

"Médias seguidas de mesma letra na coluna, não diferem entre si pelo teste de Tukey, $(P<0,05), n=5$.

Fonte: Autora, 2020.

A absorção de água pelos embriões foi afetada significativamente pela presença do $\mathrm{Hg}$ na concentração de $5 \mathrm{mM}$, a partir do primeiro dia de análise $(\mathrm{P}<0,05)$ (Tabela 2). 
Tabela 2: Teor médio de água dos embriões de Melanoxylon brauna submetidas ao tratamento controle e em solução de cloreto de mercúrio $5 \mathrm{mM}$ por dia de avaliação.

\begin{tabular}{ccc}
\hline \multirow{2}{*}{ Dia } & \multicolumn{2}{c}{ Teor de água (\%) } \\
\cline { 2 - 3 } & Água & $5 \mathrm{mM} \mathrm{HgCl} 2$ \\
\hline 0 & $14,1 \mathrm{a}$ & $14,1 \mathrm{a}$ \\
2 & $26,9 \mathrm{a}$ & $20,8 \mathrm{~b}$ \\
2 & $41,0 \mathrm{a}$ & $27,3 \mathrm{~b}$ \\
4 & $43,5 \mathrm{a}$ & $29,7 \mathrm{~b}$ \\
$4,8 \mathrm{a}$ & $31,9 \mathrm{~b}$ \\
\hline
\end{tabular}

*Médias seguidas de mesma letra na linha, não diferem entre si pelo teste de Tukey, $(P<0,05)$, $\mathrm{n}=5$.

Fonte: Autora, 2020.

Os teores de açúcares nos cotilédones decresceram no tratamento controle nas primeiras 48 horas, diferindo significativamente em relação ao tratamento de $\mathrm{Hg}$. Ao final das 96 horas, as concentrações desses carboidratos não diferiram significativamente entre ambos os tratamentos (Figura $5 \mathrm{~A}$ ). A mobilização de reservas de açúcares solúveis nos eixos embrionários foi diferenciada significativamente entre os tratamentos, com maior redução desses compostos (aproximadamente 51\%) no controle, quando comparados as sementes incubadas com Hg (Figura 5 B).

Figura 3: Teores de açúcares solúveis nos embriões de Melanoxylon brauna submetidas ao tratamento controle e a $\mathrm{HgCl}_{2} 5 \mathrm{mM}$, onde $\mathrm{A}$ : representa a mobilização dos açúcares solúveis nos cotilédones e B: nos eixos embrionários.
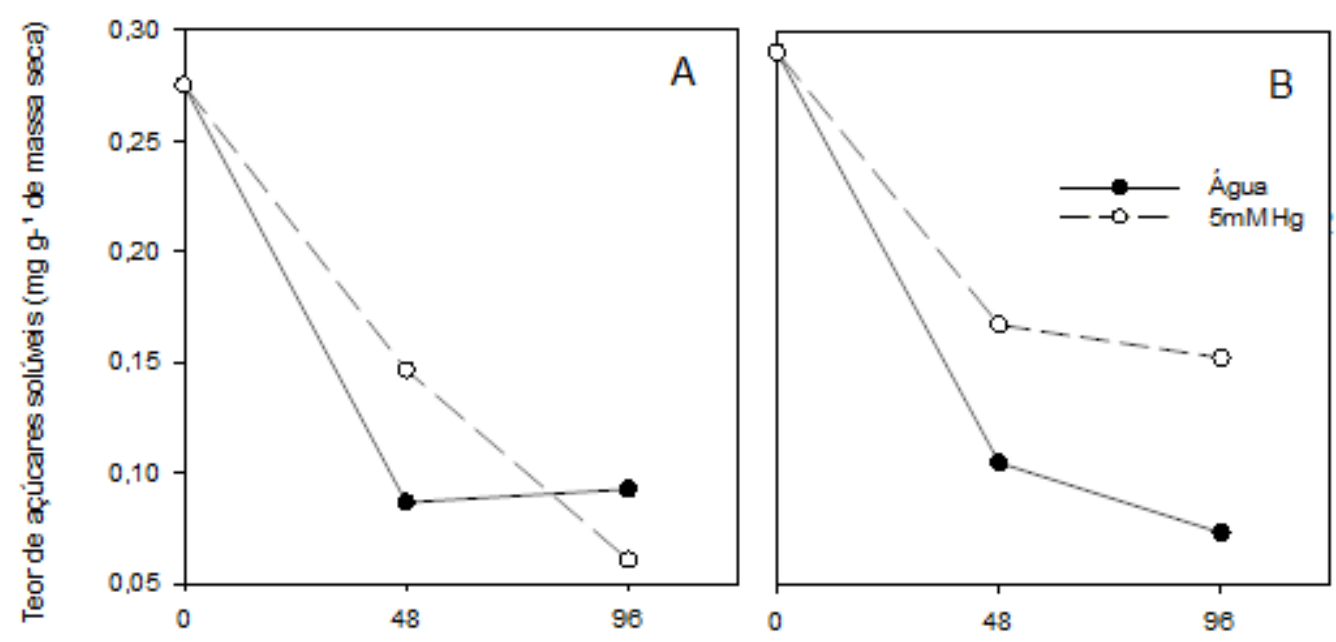

Tempo de embebiçao (horas)

Fonte: Autora, 2021. 
A reserva de amido foi afetada significativamente pela presença do $\mathrm{Hg}$ apenas nos cotilédones, em 48h de embebição (Figura 6 A). Os teores do amido nos eixos embrionários, foram similares ao longo das 96h (Figura 6 B).

Figura 4: Teores de amido nos embriões de Melanoxylon brauna submetidos ao tratamento controle e a $\mathrm{HgCl}_{2} 5 \mathrm{mM}$, onde A: representa a teores do amido nos cotilédones e B: nos eixos embrionários.

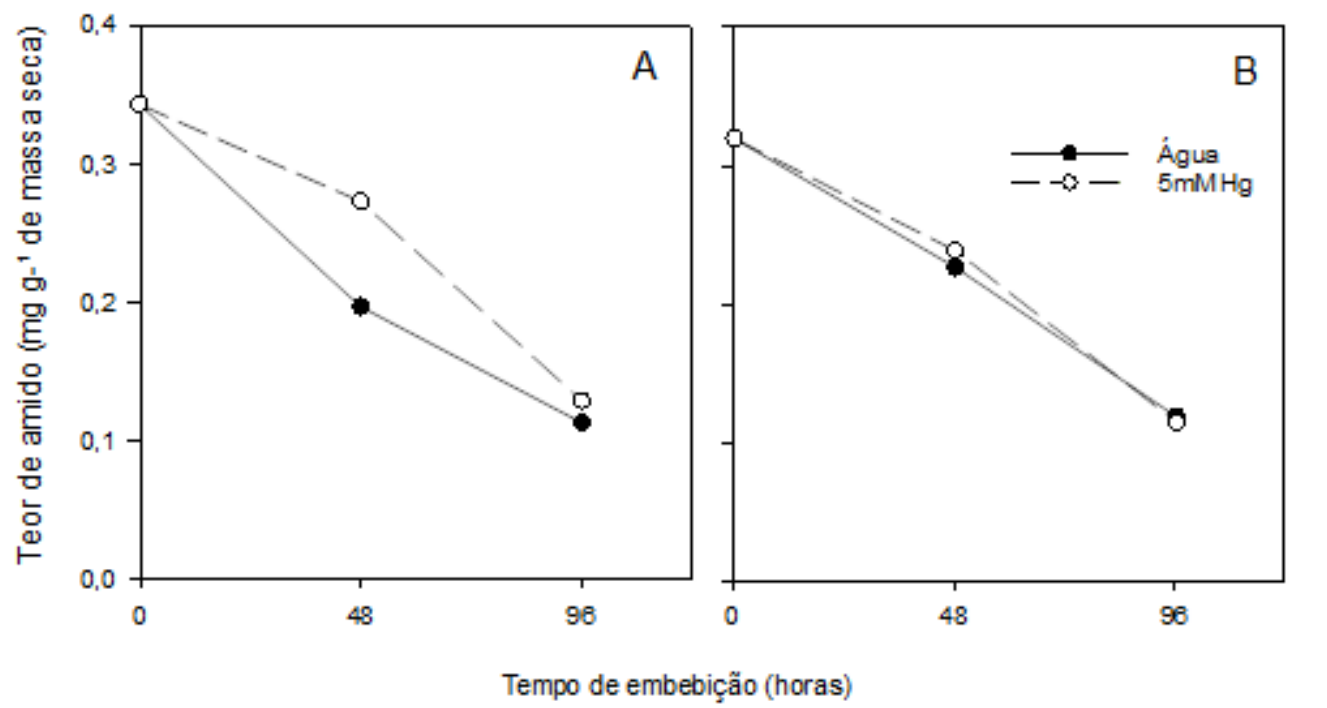

Fonte: Autora, 2021.

O teor médio original de lipídeos foi de 8,19\% nos eixos embrionários e 19,15\% nos cotilédones (Figura 7). Os valores nos cotilédones diferiram significativamente entre o tratamento controle e o de $\mathrm{Hg}$ a $5 \mathrm{mM}$ nos tempos de 48 e $96 \mathrm{~h}$ de embebição. A mobilização de lipídeos foi mais lenta nos cotilédones dos embriões tratados com $\mathrm{HgCl}_{2}$ (Figura 7 A). O mercúrio não afetou significativamente a mobilização de lipídeos nos eixos embrionários (Figura 7 B). 
Figura 5: Teores de lipídeos nos embriões de Melanoxylon brauna submetidos ao tratamento controle e a $\mathrm{HgCl}_{2} 5 \mathrm{mM}$, onde A: mobilização de lipídeos nos cotilédones e B: nos eixos embrionários.

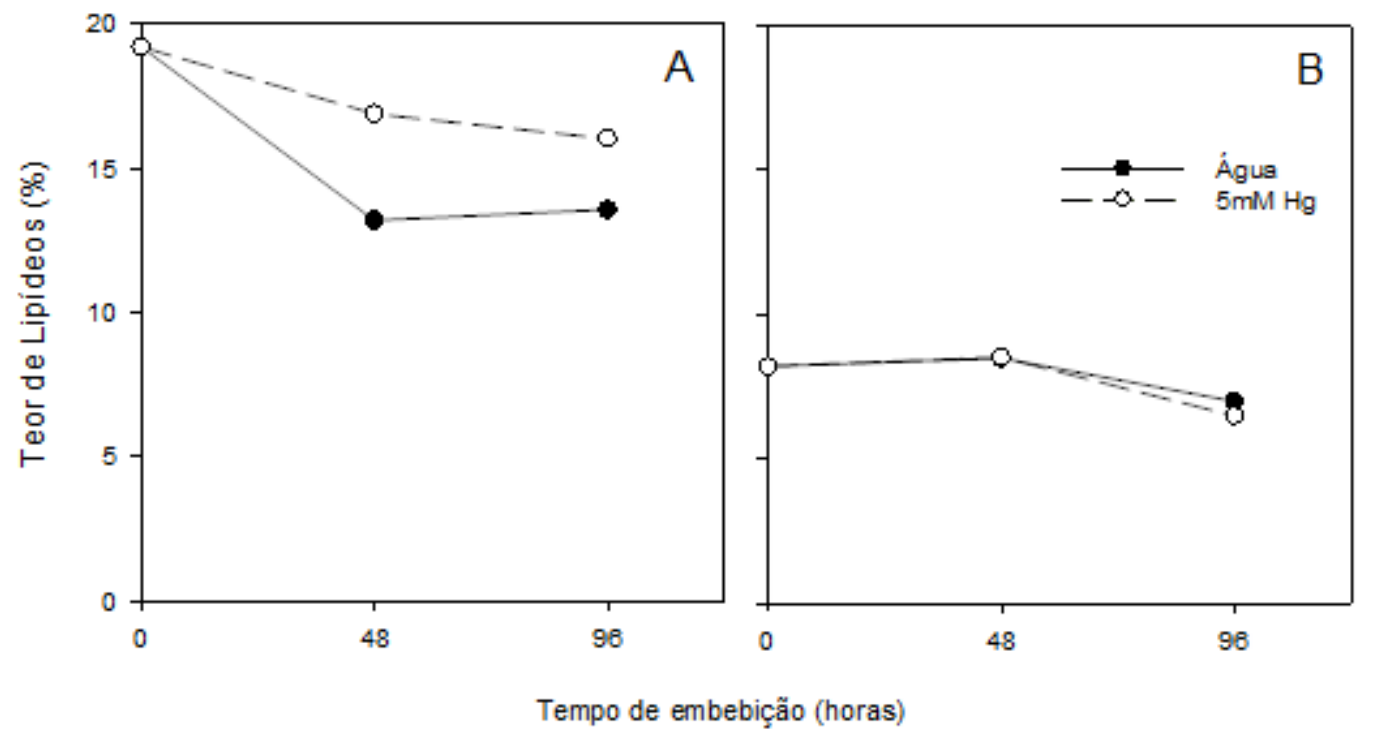

Fonte: Autora, 2021.

A mobilização de proteínas solúveis nos cotilédones ocorreu em ambos os tratamentos nas primeiras 48h, sendo mais acentuado no controle (Figura 8). Houve diferença significativa na mobilização dessa reserva entre os dois tratamentos, em 48 e 96 horas.

Figura 6: Teores de proteínas solúveis nos cotilédones de Melanoxylon brauna submetidos ao tratamento controle e a $\mathrm{HgCl}_{2} 5 \mathrm{mM}$.

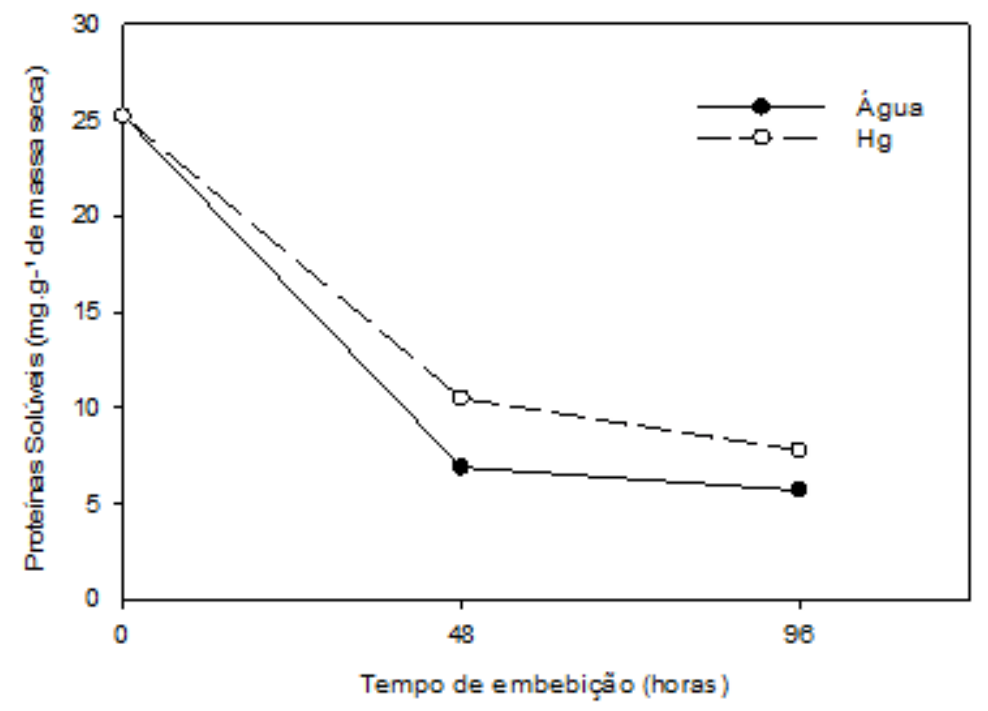

Fonte: Autora, 2021. 
As atividades das enzimas $\alpha$ - e $\beta$-amilases aumentaram significativamente nas nos dois tratamentos, em 48 e 96 horas. Entretanto, nos cotilédones tratados com $\mathrm{HgCl}_{2}$ houve redução na taxa de aumento nas atividades de ambas as enzimas (Figura 9). Após 96 horas de embebição, nas sementes tratadas com Hg, notou-se uma queda na atividade dessas enzimas de, aproximadamente, $42 \%$ e $44 \%$ respectivamente, para $\alpha$ - e $\beta$-amilase, em relação àquelas do controle.

Figura 7: Atividades das enzimas $\alpha$ - e $\beta$-amilase nos cotilédones de Melanoxylon brauna submetidos ao tratamento controle e a $\mathrm{HgCl}_{2} 5 \mathrm{mM}$; onde: $A$ representa as curvas de atividades de $\alpha$-amilase e $B$ de $\beta$-amilase.
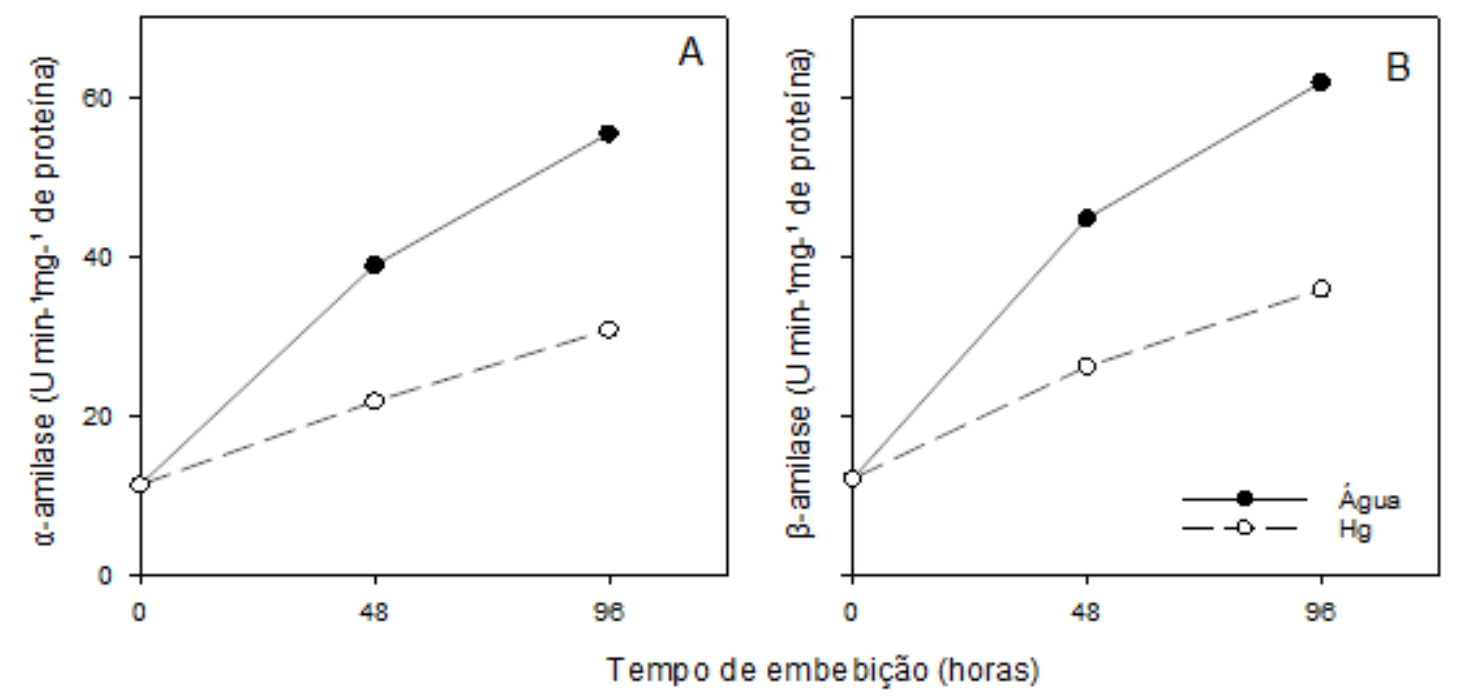

Fonte: Autora, 2021.

Diferentes concentrações de Hg provocaram alterações na morfologia e na anatomia dos embriões (Figura 10), como no alongamento do eixo embrionário no controle e nos tratamentos com Hg a 1 e 3mM (Figura 10 A-C; D-F e G-I). Diferente do observado nas sementes tratadas com $\mathrm{HgCl}_{2}$ a $5 \mathrm{mM}$ (Figura $10 \mathrm{~J}-\mathrm{L}$ ). Houve alongamento das células que compõem o eixo embrionário, sinalizando para germinação (Figura 10 B, E e H). No entanto, esse alongamento foi mais evidente no tratamento controle (Figura $10 \mathrm{C}$ ), seguido pelo tratamento com Hg a $1 \mathrm{mM}$ (Figura 10 F). Além disso, foi possível notar divisões celulares nas células do eixo embrionário (Figura 10 C, F e I). Nas células do eixo embrionário incubadas em Hg 3mM ocorreram divisões celulares, porém, os núcleos foram menos evidentes (Figura 10 I). No tratamento com $\mathrm{Hg} 5 \mathrm{mM}$, não foram observadas divisões celulares (Figura $10 \mathrm{~K}$ ) e ocorreu coalescência do conteúdo celular (Figura 10 L). 
Figura 8: Cortes longitudinais de sementes de Melanoxylon brauna, coradas com azul de toluidina. A-C: tratamento controle; D-F: $1 \mathrm{mM} \mathrm{HgCl}_{2}$; G-I: $3 \mathrm{mM} \mathrm{HgCl}_{2}$ e J-L $5 \mathrm{mM} \mathrm{HgCl}_{2}$. Barras

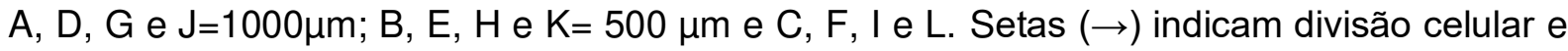
as setas com barra $(\rightarrow \mid)$, indicam coalescênscia das células no tratamento com $5 \mathrm{mM}$ de $\mathrm{HgCl}_{2}$.

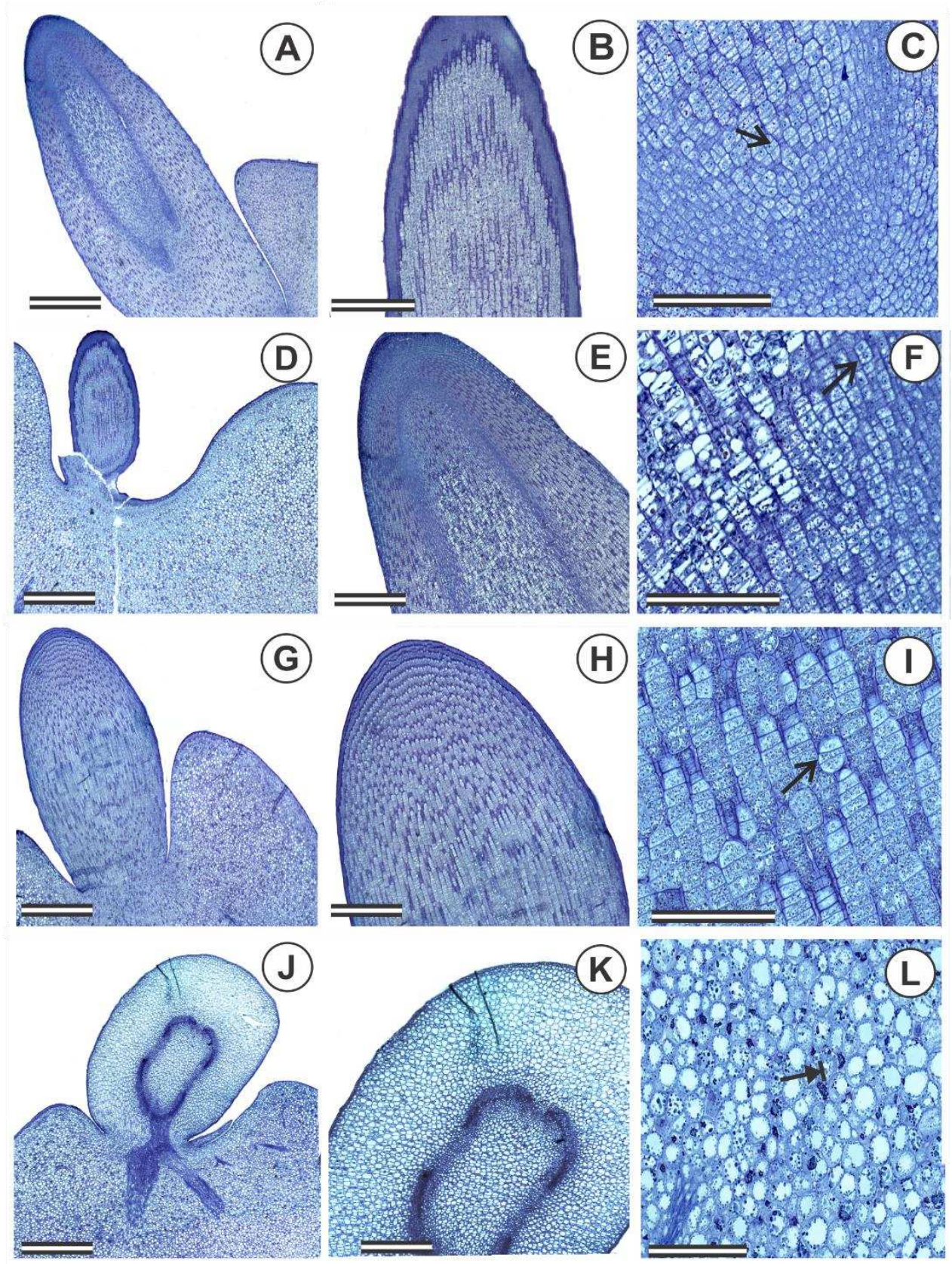

Fonte: Autora, 2021.

Nas sementes, o malonaldeído (MDA) é considerado um biomarcador de estresse oxidativo e indica a intensidade de danos causados aos lipídeos das membranas celulares (YONAR e YONAR, 2010; JACOBY et al., 2012). Ao avaliar a 
concentração de MDA, observou-se estabilidade na concentração desse composto nos embriões embebidos em água (Figura 11) em 48 e 96 horas de embebição. Nas sementes tratadas com $\mathrm{HgCl}_{2}$, a concentração desse composto decresceu em 48 horas, permanecendo constante até 96 horas. Quando comparados aos embriões tratados com água, a produção de MDA diferiu significativamente nas 48 e 96 horas, sendo aproximadamente $21 \%$ maior em relação aos embriões embebidos em mercúrio.

Figura 9: Concentração de Malonaldeído nos cotilédones de Melanoxylon brauna no tratamento controle e em $\mathrm{HgCl}_{2} 5 \mathrm{mM}$.

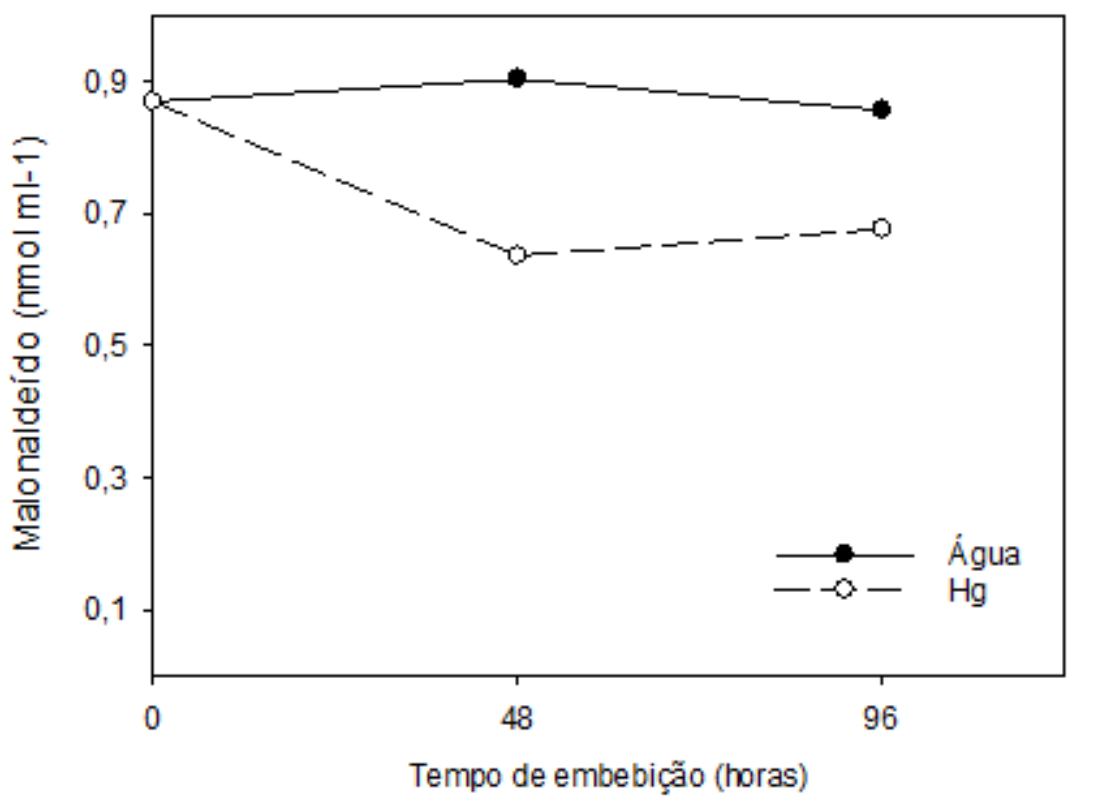

Fonte: Autora, 2021.

Diante dos resultados anteriores, para elucidar a dúvida se o Hg leva a morte ou apenas interfere no processo germinativo, as sementes foram incubadas por 30 minutos em solução de azul de Evans 1\%. Esse corante é utilizado como indicador de células mortas ou programadas para morrer. $\mathrm{O} \mathrm{Hg}$ não causou a morte das células do eixo embrionário no tempo de $96 \mathrm{~h}$. $\mathrm{O} \mathrm{Hg}$ interferiu apenas na entrada de água nas sementes, retardando a protrusão da raiz primária (Figura 12), como se observa no tratamento controle. No tratamento com $\mathrm{HgCl}_{2} 5 \mathrm{mM}$ não foi observado o alongamento do eixo durante o período de $96 \mathrm{~h}$. Portanto, não houve a germinação dentro deste período para as sementes tratadas com $5 \mathrm{mM}$ dessa solução (Figura $10 \mathrm{~J}$ e $12 \mathrm{D}$ ). Diferentemente do que ocorreu com o tratamento controle, no qual o eixo embrionário foi o que apresentou maior alongamento (figuras $10 \mathrm{~A}$ e $12 \mathrm{C}$ ) 
As sementes do controle e as incubadas com $\mathrm{HgCl}_{2} 5 \mathrm{mM}$ aumentaram suas taxas respiratórias em 48 horas. Todavia, o consumo de oxigênio decresceu significativamente $(\mathrm{P}<0,05)$ no tratamento de $\mathrm{HgCl}_{2}$ em 96 horas (Figura $12 \mathrm{G}$ ). A taxa de consumo de oxigênio continuou a se elevar nas sementes do tratamento controle. Ao final dos 4 dias as sementes germinadas em $\mathrm{HgCl}_{2}$ apresentaram atividade respiratória 5,8 vezes menor em relação às do tratamento controle (Figura 12 G). 
Figura 10:. Respiração de sementes de Melanoxylon brauna incubadas em água ou em solução de $\mathrm{HgCl} 25 \mathrm{mM}$, por zero, 48 e 96 horas. A, B e C (água), D, E e F (Hg). Barras A e $\mathrm{D}=1,3 \mathrm{~mm}$; $\mathrm{B}, \mathrm{C}, \mathrm{E}$ e $\mathrm{F}=1,25 \mathrm{~mm}$. G: Interferência do $\mathrm{Hg}$ na respiração de sementes de Melanoxylon brauna. (*) destaca o alongamento do eixo embrionário).
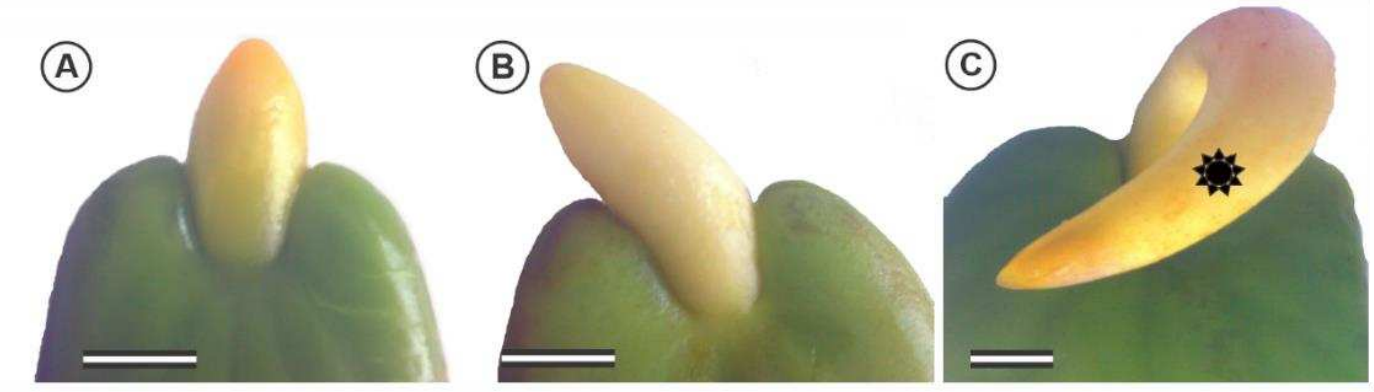

(D)

(E)

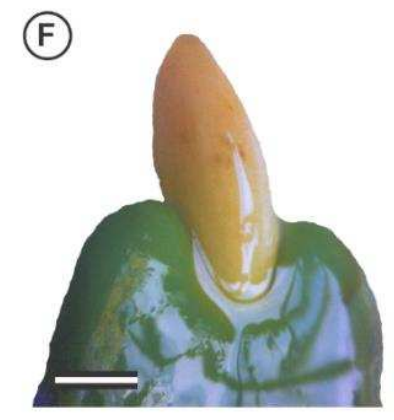

(G)

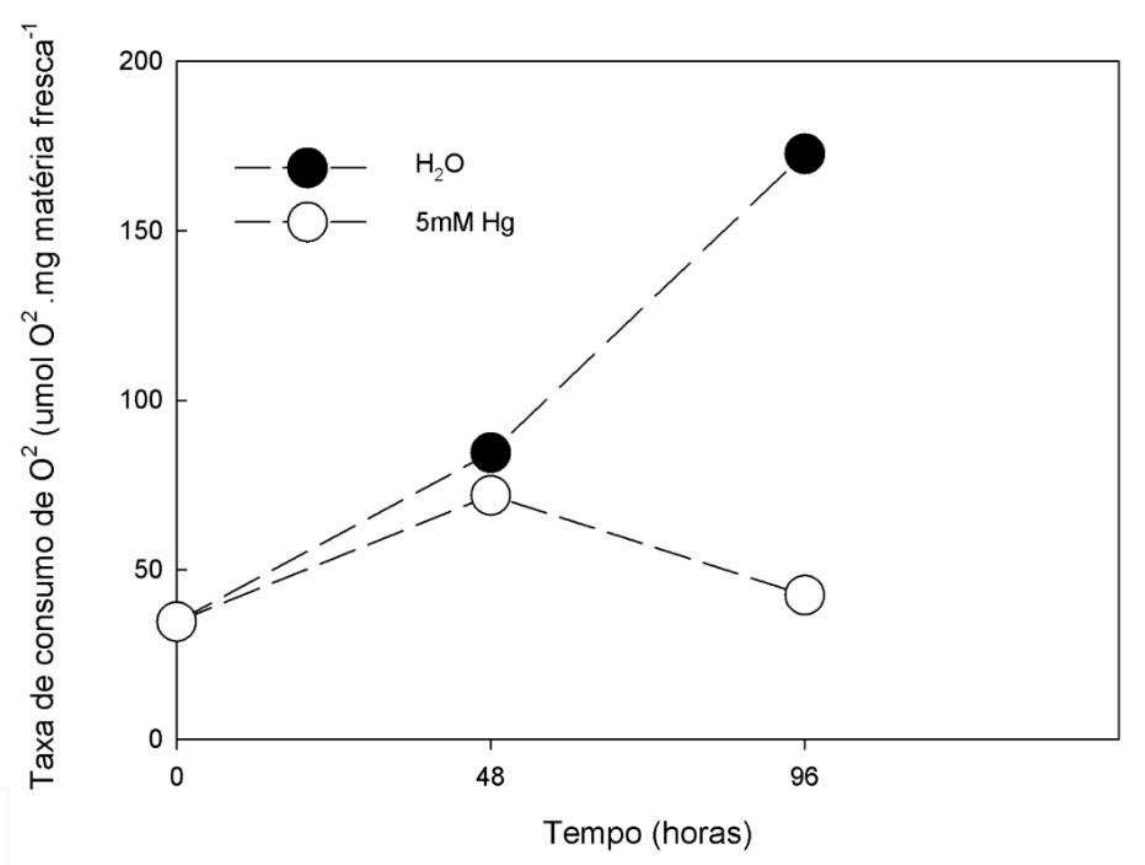

Fonte: Autora, 2021. 


\section{DISCUSSÃO}

A germinação das sementes é o estágio mais crítico no estabelecimento da muda, afetada por interações genéticas e ambientais e por fatores bióticos e abióticos (MADEJÓN et al., 2015; MOOSAVI et al., 2012). A absorção de água pelo embrião marca o começo desse processo e a protrusão da raiz primária sinaliza o fim da germinação (NONOGAKI et al., 2010). Ainda que as plantas possuam recursos de proteção contra diversos tipos de perturbação, durante a germinação e o crescimento inicial elas são menos tolerantes (REETHA et al., 2012; AERY e SANKAR, 2012; JAIN, 2013). A presença de uma substância tóxica pode prejudicar esse processo e interferir na sobrevivência dos organismos (RODRIGUES, et al., 2016).

De acordo com a concentração em que se encontra no meio, o mercúrio afeta a germinação das sementes de braúna de formas diferentes. Em baixas concentrações as sementes germinaram de forma semelhante ao controle. $\mathrm{O} \mathrm{Hg} \mathrm{em}$ baixas concentrações também não afetou significativamente a germinação de sementes de Albizia lebbeck (IQBAL et al., 2014), Cajanus cajan (PATNAIK e MOHANTY, 2013), Brassica napus (REZAEl et al., 2013) e Vigna radiata (MUHAMMAD et al., 2015)

Em concentrações mais elevadas, este elemento traço afetou negativamente a germinação de sementes de braúna, semelhante ao que já foi observado para outras espécies (YÁÑEZ-ESPINOSA et al., 2020). O reflexo no atraso da germinação foi verificado pelo IVG. Esse parâmetro expressa o vigor das sementes, indicando se houve ou não retardo da germinação (HE et. al., 2008; LIU et al., 2012). O tratamento das sementes com $\mathrm{HgCl}_{2}$ não causou a morte das sementes de braúna, no entanto afetou significativamente sua porcentagem de germinação e IVG. Essa interferência negativa está ligada em parte à hidratação das sementes e a fatores metabólicos. Resultados semelhantes foram relatados com Triticum aestivum e Cucumis sativus (JAIN et al., 2008; MUNZUROGLU \& GECKIL, 2002). Esse atraso na germinação permite inferir, pelo teor de água (Tabela 3), e que o Hg interfere na entrada de água das sementes.

Uma das formas que a água se move nos tecidos vegetais é pela movimentação transmembrana. Esse transporte ocorre por dois mecanismos: difusão de moléculas de água através da bicamada lipídica e por meio das aquaporinas (TAIZ e ZEIGER, 2013). As aquaporinas (AQPs) são essenciais para manter o equilíbrio 
osmótico nos vegetais, além de desempenharem processos de desintoxicação e translocação de nutrientes nesses organismos (CHAUMONT e TYERMAN, 2017). Além de potencialmente tóxico, o $\mathrm{Hg}$ é apontado como bloqueador da atividade das AQPs. Compostos a base de Hg também diminuíram a velocidade de embebição e a porcentagem de germinação de sementes de Arabidopsis thaliana (VANDER WILLIGEN et al., 2006).

Sementes de espécies florestais, como plátano (Platanus occidentalis) e pinheiros (Pinus taeda e Pinus echinata), também apresentaram redução nas porcentagens de germinação quando tratados com compostos a base de $\mathrm{Hg}$. A menor hidratação dos embriões tratados com $\mathrm{HgCl}_{2}$ corrobora os resultados de outros pesquisadores a respeito da influência do $\mathrm{Hg}$ na absorção de água, pelo bloqueio no funcionamento das AQPs (OBROUCHEVA et al., 2012; NOVIKOVA et al., 2014; CARDOSO et al., 2015).

A redução na absorção de água afeta a germinação, visto que aumenta o tempo necessário para a essa etapa ocorra, sendo esse um período crítico da expansão do embrião, reduz a taxa respiratória, a quebra de compostos de reserva e a síntese de novas enzimas e moléculas. Com metabolismo mais lento, a degradação das reservas que viriam a ser usadas para o crescimento do embrião também não ocorre da maneira usual.

$\mathrm{Na}$ germinação, o embrião adquire energia, principalmente, por meio da ativação das rotas da glicólise, do ciclo de Krebs e das vias das pentosesmonofosfatada (BEWLEY et al., 2013; HAN et al., 2014; HE et al., 2015). Na absorção de água as reservas de nutrientes contidas no embrião e nos cotilédones são usadas para fornecer metabólitos para a respiração. No entanto, a presença de elementos traço pode influenciar na atividade de enzimas envolvidas nesse processo, como a $\alpha$ amilase e $\beta$-amilase (KO et al, 2012; LIU et al, 2005; HE, et al., 2008). Portanto, a interferência na velocidade de entrada de água nas sementes também afeta a ação dessas enzimas hidrolíticas. A interferência da presença de elementos traço na atividade dessas enzimas foi também demonstrado em Catharanthus roseus (PANDEY ET AL., 2007), Brassica campestris (SINGH et al. 2011) e Pisum sativum (DESWAL e LAURA, 2018).

Em condições regulares de embebição, o consumo dos carboidratos aumenta conforme ocorre a ativação do metabolismo das sementes (BEWLEY et al., 2013). Alguns estudos indicaram que elementos traço causam a inibição da germinação e 
desenvolvimento das sementes por meio do bloqueio da mobilização dos compostos de reservas e degradação das atividades proteolíticas (ADREES et al. 2015; KARMOUS et al. 2015; BASZYNSKI, 2014).

Os carboidratos solúveis (glicose, frutose, sacarose e rafinose) são normalmente encontrados nos eixos embrionários e cotilédones e utilizados para produção de energia (BEWLEY et al., 2013). No entanto o mercúrio afeta a mobilização e a disponibilidade dessas reservas, causando a redução no crescimento e na produção de biomassa (SETHY e GHOSH, 2013), como foi mostrado pelos resultados do presente estudo (Figura 5 e Tabela 3). Os teores de açúcares solúveis nos eixos embrionários de Melanoxylon brauna, embebidos em água, reduziram. Enquanto na presença de $\mathrm{Hg}$, a inibição da absorção causada por este elemento reduziu em $49 \%$ o teor das reservas desses carboidratos nos eixos embrionários.

O Hg também interferiu na retomada da atividade das amilases, pois na presença do $\mathrm{Hg}$ o teor amido foi reduzido em menor quantidade. Com as fontes de nutrientes limitadas, diminuiu a porcentagem de germinação, como observado nos embriões embebidos em $\mathrm{HgCl}_{2}$ (Figura 2), confirmado pela maior atividade das enzimas $\alpha$ - e $\beta$-amilase, maior nas sementes tratadas com a solução controle (Figura 9).

Uma explicação para a interferência dos metais pesados na atividade enzimática se relaciona à entrada de água e à produção de energia a partir das reservas disponíveis no embrião. Outra hipótese para a menor porcentagem de germinação das sementes tratadas com mercúrio é a sua toxicidade. Elementos traço, como o $\mathrm{Hg}$, após entrarem nas sementes induzem o estresse oxidativo que leva a danos celulares (KRANNER et al., 2011, KUNJAM et al., 2015; NAGATI et al., 2015). Esses elementos induzem a produção descontrolada de EROs em nível tóxico às células (HONG et al., 2015). Essas podem desestabilizar compostos celulares comprometendo a funcionalidade da parede celular e da membrana plasmática (MITTLER, 2011). A produção de MDA está associada à peroxidação lipídica. Nas sementes, a peroxidação lipídica caracteriza a perda da seletividade das membranas celulares na germinação (BEWLEY et al., 2013) e está associada a queda da atividade das enzimas do sistema antioxidante (SYTAR et al., 2013). Contrariando o que era esperado, nos embriões de Melanoxylon brauna tratados com $\mathrm{Hg}$ ao longo das 96 horas de avaliação, houve menor produção de MDA, quando comparados aos embriões tratados com água. Uma das explicações para este comportamento pode 
ser a queda na produção de peróxido de hidrogênio. Outros estudos relacionando sementes no estágio de germinação com elementos traço verificaram o aumento da concentração de MDA, levando à perda de viabilidade em Vicia faba, Allium sativum (UNYAYAR et al., 2006), Arabidopsis thaliana (CHO e SEO, 2005), Triticum spp. (LI et al., 2007), Vigna unguiculata (ERIYARNREMU et al., 2007) e Suaeda salsa (WU et al., 2012).

A baixa produção de MDA observada nas sementes tratadas com $\mathrm{Hg}$, também pode ser explicada por um possível controle da formação ou aumento da degradação de peróxidos de hidrogênio pelo sistema de defesas antioxidantes da semente. $O$ fato de que as concentrações de MDA, um subproduto direto da peroxidação lipídica, não tenham se elevado significativamente com $\circ \mathrm{Hg}$, indica que não ocorreram danos oxidativos graves (POURRUT et al., 2013). Tal informação leva a concluir que as alterações verificadas na germinação pela aplicação do metal provavelmente se deram devido a interferência no processo de embebição das sementes durante esse período.

Outro sintoma visível da interferência do $\mathrm{Hg}$ na expansão dos embriões foi a diminuição no comprimento médio dos eixos embrionários que foi quase três vezes menor do que os mantido em água. Observações semelhantes foram verificadas por Abraham e Damodaran (2012) com sementes de Arachis hyposea. Metais como mercúrio, chumbo e arsênio podem interromper divisões celulares por causarem perturbações no fuso mitótico, promovendo redução no crescimento ou ausência da radícula (LIU et al., 2014; MUCCIFORA \& BELLANI, 2013). Nesse caso, o Hg foi considerado mais potente do que As e Pb (PATRA et al., 2004).

Dessa forma, sugere-se que a maior quantidade do elemento traço poderá resultar em menor germinação e menor velocidade de germinação. O aumento no tempo necessário para germinação, pode favorecer o ataque de microrganismos do solo, que ao se associarem às sementes podem levar à sua morte. Assim, a redução da porcentagem de germinação, a menor velocidade de germinação e a morte das sementes em decorrência do ambiente pode afetar a sobrevivência natural da espécie. 


\section{CONCLUSÕES}

O mercúrio altera o padrão de embebição das sementes de Melanoxylon brauna Schott, causando redução na germinação e no vigor.

O $\mathrm{Hg}$ reduz a atividade das enzimas $\alpha$ e $\beta$-amilase.

$\mathrm{OHg}$ afeta a atividade respiratória.

$\mathrm{O} \mathrm{Hg}$ interfere negativamente no crescimento e alongamento dos eixos embrionários de Melanoxylon brauna.

A concentração de cloreto de mercúrio de até $5 \mathrm{mM}$ não é capaz de levar as sementes à morte. Mas atrasa a germinação.

O Hg age principalmente na velocidade de hidratação das sementes durante a germinação. 


\section{REFERÊNCIAS BIBLIOGRÁFICAS}

ABDELGAWAD, Hamada et al. High salinity induces different oxidative stress and antioxidant responses in maize seedlings organs. Frontiers in plant science, v.7, p. 276, 2016.

ABRAHAM, K.; DAMODHARAM, T. Effect of the $\mathrm{HgCl} 2$ on germination and seedling growth of Arachies hypogiea L. Annals of Biological Research, v. 3, n. 7, p. 32973299, 2012.

ACHARYA, S.; SHARMA, D. K. Study on the effects of heavy metals on seed germination and plant growth on Jatropha curcas. International Journal of Agricultural Science Research, v.3, n. 3, p. 31-34, 2014.

ADREES, M.; ALI et al. The effect of excess copper on growth and physiology of important food crops: a review. Environmental Science and Pollution Research, v. 22, n. 11, p. 8148-8162, 2015.

AERY, N. C.; SARKAR, S. Metal species vis-à-vis seed germination and early seedling growth responses in soybean. Journal of Chemical, Biological and Physical Sciences (JCBPS), v. 2, n. 2, p. 763, 2012.

AGENCY FOR TOXIC SUBSTANCES AND DISEASE REGISTRY - ATSDR. Substance priority list. set. 2017. Disponível em: < https://www.atsdr.cdc.gov/spl/>. Acesso em: 30 de mai. de 2019.

AHAMMAD, S. J.; SUMITHRA, S.; SENTHILKUMAR, P. Mercury uptake and translocation by indigenous plants. Rasayan Journal of Chemistry, v. 11, n. 1, p. 112, 2018.

AHMAD, M. S. A. et al. Lead (Pb) - Induced regulation of growth, photosynthesis, and mineral nutrition in maize (Zea mays L.) plants at early growth stages. Biological trace element research, v. 144, n. 1-3, p. 1229-1239, 2012.

AHMAD, P.; JALEEL, A. C.; SALEM, A. M.; NABI, G.; SHARMA, S. Roles of enzymatic and nonenzymatic antioxidants in plants during abiotic stress. Critical Reviews in Biotechnology, v. 30, p. 161 - 175, 2010.

AHMAD, R. et al. Phytoremediation potential of hemp (Cannabis sativa L.): identification and characterization of heavy metals responsive genes. CLEAN-Soil, Air, Water, v. 44, n. 2, p. 195-201, 2016.

ALI, Z. et al. Enrichment, risk assessment, and statistical apportionment of heavy metals in tannery-affected areas. International Journal of Environmental Science and Technology, v. 12, n. 2, p. 537-550, 2015.

ALVES, L. R. et al. Cadmium stress related to root-to-shoot communication depends on ethylene and auxin in tomato plants. Environmental and Experimental Botany, v. 134, p. 102-115, 2017. 
AGÊNCIA NACIONAL DE ÁGUAS (Brasil). Encarte Especial Sobre a Bacia do Rio Doce - Rompimento da Barragem em Mariana - MG. Superintendência de Planejamento de Recursos Hídricos - SPR/Ministério do Meio Ambiente, Brasília DF, 2016.

ANJUM, S. A. et al. Osmoregulation and antioxidant production in maize under combined cadmium and arsenic stress. Environmental Science and Pollution Research, v. 23, n. 12, p. 11864-11875, 2016.

AROCA, R.; PORCEL, R.; RUIZ-LOZANO, J. M. Regulation of root water uptake under abiotic stress conditions. Journal of experimental botany, v. 63, n. 1, p. 43-57, 2012.

ATAÍDE, G. M.; BORGES, E.E.L.; PICOLI, E.A.T.; FILHO, A.T.L.; FLORES, A.V. Changes in seed reserves of Melanoxylon brauna Schott. (Fabaceae Caesalpinoideae) during germination at different temperatures. Revista Brasileira de Ciencias Agrarias, v. 12, n. 3, p. 372-379, 2017.

ATAIIDE, G. M.; BORGES, E.L.; FILHO, A. L. Alterações fisiológicas e biométricas em sementes de Melanoxylon brauna Schott durante a germinação em diferentes temperaturas. Revista Árvore, v. 40, n. 1, p. 61-70, 2016.

AZZAM, A. M. et al. Removal of $\mathrm{Pb}, \mathrm{Cd}, \mathrm{Cu}$ and $\mathrm{Ni}$ from aqueous solution using nano scale zero valent iron particles. Journal of Environmental Chemical Engineering, v.4, n. 2, p. 2196-2206, 2016.

BAKER, A.J.M. Metal tolerance. New Phytologist, v.106, p.93-111, 1987.

BARON, D.; FERREIRA, G.; BOARO, C. S. F.; MISCHAN, M. M. Evalution of substrates on the emergence of "araticum-de-terra-fria" (Annona emarginata (Schltdl.) H. Rainer) seedlings. Revista Brasileira de Fruticultura, v. 33, n. 2, p. 575-586, 2011.

BARREIROS, A. L. B. S.; DAVID, J. M. Estresse oxidativo: relação entre geração de espécies reativas e defesa do organismo. Química Nova, v. 29, p. 113 - 123, 2006.

BASZYŃSKI, Tadeusz. Interference of $\mathrm{Cd} 2+$ in functioning of the photosynthetic apparatus of higher plants. Acta Societatis Botanicorum Poloniae, v. 55, n. 2, p. 291-304, 2014.

BEWLEY, J. Derek et al. Germination. In: Seeds. Springer, New York, NY, 2013. p. 133-181.

BEWLEY, J.D.; BLACK, M. Seeds: Physiology of development and germination. 2. ed. New York: Plenum Press, 1994. 445 p.

BORGES, E. E. L.; ATAÍDE, G. M. MATOS, A. C. B. Micropilar and embryonic events during hydration of Melanoxylon brauna Schott seeds. Journal of Seed Science, v. 37, p. 192 - 201, 2015.

BORGES, E.E.L. Comportamento bioquímico e fisiológico de sementes florestais nativas durante a embebição. 2003. $100 \mathrm{f}$. Tese (Doutorado em Ecologia e Recursos Naturais) - Universidade Federal de São Carlos, São Carlos, 2003. 
BOTELHO, L. S. Fungos Associados às Sementes de Ipê-amarelo (Tabebuia serratifolia), Ipê-roxo (Tabebuia impetiginosa). Summa Phytopathologica, v.34, n.4, p.343-348, Piracicaba: ESALQ, 2008.

BRADFORD, M. M. A rapid and sensitive method for the quantitation of microgram quantities of protein utilizing the principle of protein-dye binding. Analytical Biochemistry, v. 72, p. 248 - 254, 1976.

BUCKERIDGE, M. S.; DIETRICH, S. M. C. Galactomanans from Brazilian legume seeds. Revista Brasileira de Botânica, v. 13, p. 109-112, 1990.

CARDOSO, A. A.; BORGES, E. E. L.; SOUZA, G. A.; SILVA, C. J.; PIRES, R. M. O.; DIAS, D. C. F. S. Seed imbibition and germination of Plathymenia reticulata Benth. (Fabaceae) affected by mercury: possible role of aquaporins. Acta Botanica Brasilica, v. 29, p. 285 - 291, 2015.

CETESB, 2017. Texto explicativo: Relação no Estado de Áreas Contaminadas de São Paulo. Dez 2017. Disponível em: <https://www.cetesb.sp.gov.br/areascontaminadas/wp-content/uploads/sites/17/2018/01/Texto-explicativo.pdf $>$. Acesso em: 03 de jun. de 2019.

CHANCE, B., WILLIAMS, G.R. The respiratory chain and oxidative phosphorylation. Advances Enzymology Related Areas Molecular Biology, v.17, p.65-134, 1956.

CHEN, J. et al. Copper induced oxidative stresses, antioxidant responses and phytoremediation potential of Moso bamboo (Phyllostachys pubescens). Scientific reports, v. 5, p. 13554, 2015.

CHEN, L. et al. Cytological and transcriptome analyses reveal abrupt gene expression for meiosis and saccharide metabolisms that associated with pollen abortion in autotetraploid rice. Molecular Genetics and Genomics, v. 293, n. 6, p. 1407-1420, 2018.

$\mathrm{CHO}$, Un-Haing; SEO, Nam-Ho. Oxidative stress in Arabidopsis thaliana exposed to cadmium is due to hydrogen peroxide accumulation. Plant Science, v. 168, n. 1, p. 113-120, 2005.

CHOUDHARY, R. C. et al. Synthesis, characterization, and application of chitosan nanomaterials loaded with zinc and copper for plant growth and protection. In: Nanotechnology. Singapore, p. 227-247, Springer, 2017.

CLEMENS, S.; MA, J. F. Toxic heavy metal and metalloid accumulation in crop plants and foods. Annual review of plant biology, v. 67, p. 489-512, 2016.

CORTE, V. B. et al. Estudo enzimático da deterioração de sementes de Melanoxylon brauna submetidas ao envelhecimento natural e acelerado. Revista Brasileira de Sementes, v. 32, n. 1, p. 83-91, 2010.

CREPALDI, M. O. S.; PEIXOTO, A. L. Use and knowledge of plants by "Quilombolas" as subsidies for conservation efforts in an area of Atlantic Forest in Espírito Santo State, Brazil. Biodiversity and Conservation, v. 19, n. 1, p. 37, 2010. 
DA SANTOS SILVA, J. H. et al. Distinção de grupos ecológicos de espécies florestais por meio de técnicas multivariadas. Revista Árvore, v. 28, n. 3, p. 387-396, 2004.

DAVENPORT, Andrew. Trace elements in chronic kidney disease. In: Chronic renal disease. Academic Press, 2020. p. 703-717.

DEMIDCHIK, Vadim. Mechanisms of oxidative stress in plants: from classical chemistry to cell biology. Environmental and experimental botany, v. 109, p. 212228, 2015.

DEMIRAL, T.; TÜRKAN, I. Comparative lipid peroxidation, antioxidant defense systems and proline content in roots of two rice cultivars differing in salt tolerance. Environmental and experimental botany, v. 53, n. 3, p. 247-257, 2005.

DE SOUZA, V.; KONRAD, O.; GONÇALVES JUNIOR, A.C. Contaminação por chumbo, riscos, limites legais e alternativas de remediação. Veredas do Direito, v. 13, n. 25, p. $249-276,2017$.

DONG, J.; WU, F.; ZHANG, G. Influence of cadmium on antioxidant capacity and four microelement concentrations in tomato seedlings (Lycopersicon esculentum). Chemosphere, v. 64, n. 10, p. 1659-1666, 2006.

DU, Z.; BRAMLAGE, W. J. Modified thiobarbituric acid assay for measuring lipid oxidation in sugar-rich plant tissue extracts. Journal of Agricultural and Food Chemistry, v. 40, n. 9, p. 1566-1570, 1992.

DUBOIS, M.; GILLES, K. A.; HAMILTON, J. K.; REBERS, P. A.; SMITH, F. Colorimetric method for determination of sugars and related substances. Annalitical Chemistry, v. 28 , p. $350-356,1956$.

EL RASAFI, T. et al. The effect of $\mathrm{Cd}, \mathrm{Zn}$ and $\mathrm{Fe}$ on seed germination and early seedling growth of wheat and bean. Ekológia (Bratislava), v. 35, n. 3, p. 213-223, 2016.

ESTABROOK, R.W. Mitochondrial respiratory control and the polarographic measurements of ADP/O ratios. Methods Enzymology, v.10, p.41-47, 1967.

FARIA, J. M. R.; BUITINK, J.; VAN LAMMEREN, A. A. M.; HILHORST, H. W. M. Changes in DNA and microtubules during loss and re-establishment of desiccationtolerance in germinating Medicago truncatula seeds. Journal of Experimental Botany, v. 56, p. 2119 - 2130, 2005.

FLORES, A. V. Germinação de sementes de Melanoxylon brauna (Schott) sob diferentes temperaturas: aspectos morfofisiológicos e enzimáticos. 2011. 66fls. (Tese - Doutorado em Ciência Florestal) - Universidade Federal de Viçosa, Viçosa, 2011.

FLORES, A.V.; BORGES, E. E. L.; GUIMARÃES, V. M.; GONÇALVES, J. F. C.; ATAÍDE, C. M.; BARROS, D. P. Atividade enzimática durante a germinação de sementes de Melanoxylon brauna Schott sob diferentes temperaturas. Cerne, v.20, n.2, p.401-408, 2014. 
GAJEWSKA, E.; SKLODOWSKA, M. Differential biochemical responses of wheat shoots and roots to nickel stress: antioxidative reactions and proline accumulation. Plant Growth Regulation, v. 54, p. 179 - 188, 2008.

GILL, S. S.; TUTEJA, N. Reactive oxygen species and antioxidant machinery in abiotic stress tolerance in crop plants. Plant Physiology and Biochemistry, v. 48, p. 909 930, 2010.

GORDIN, C.R.B.; MARQUES, R.F.; MASETTO, T.E.; SCALON, S.D.P.Q. Germinação, biometria de sementes e morfologia de plântulas de Guizotia abyssinica Cass. Journal of Seed Science, v.34, n.4, 2012.

GREIPSSON, S. Phytoremediation. Nature Education Knowledge, v.2, p.3-7, 2011.

GUPTA, D. K.; HUANG, H. G.; CORPAS, F. J. Lead tolerance in plants: strategies for phytoremediation. Environmental Science and Pollution Research, v. 20, n. 4, p. 2150-2161, 2013.

GUPTA, N. et al. Trace elements in soil-vegetables interface: Translocation, bioaccumulation, toxicity and amelioration-A review. Science of the Total Environment, v. 651, p. 2927-2942, 2019.

HANDA, N. et al. Selenium ameliorates chromium toxicity through modifications in pigment system, antioxidative capacity, osmotic system, and metal chelators in Brassica juncea seedlings. South African Journal of Botany, v. 119, p. 1-10, 2018.

HATJE, V. et al. The environmental impacts of one of the largest tailing dam failures worldwide, Scientific Reports, v.7, n. 1, p.01-13, 2017.

HE, J. et al. Effects of Cadmium Stress on Seed Germination, Seedling Growth and Seed Amylase Activities in Rice (Oryza sativa). Rice Science, v. 15, n. 4, p. 319-325, 2008.

HONG, S.; SOWNDHARARAJAN, K.; JOO, T.; LIM, C.; CHO, H.; KIM, S.; KIM, G.; JHOO, J. Ethanol and supercritical fluid extracts of hemp seed (Cannabis sativa L.) increase gene expression of antioxidant enzymes in HepG2 cells. Asian Pacific Journal of Reproduction, v. 4, p. 147 - 152, 2015.

HOODA, Peter S. Assessing bioavailability of soil trace elements. Trace elements in soils, p. 227-265, 2010.

$\mathrm{HU}$, Yuanan et al. Assessing heavy metal pollution in the surface soils of a region that had undergone three decades of intense industrialization and urbanization. Environmental Science and Pollution Research, v. 20, n. 9, p. 6150-6159, 2013.

IOSOB, G. A. et al. Study of Phytotoxic effects of $\mathrm{Cu}^{2+}$ and $\mathrm{Cd}^{2+}$ on Seed Germination and Chlorophyll Pigments Content to the Bell Pepper. Revista Chimie (Bucharest), v. 70, p. $1416,2019$.

INSTITUTO BRASILEIRO DO MEIO AMBIENTE E DOS RECURSOS NATURAIS RENOVÁVEIS - IBAMA. Disponível em: https://www.ibama.gov.br/. Acesso em: 25 de nov. de 2019. 
IQBAL, M. Z.; SHAFIQ, M.; ATHAR, M. Phytotoxic effects of mercury on seed germination and seedling growth of Albizia lebbeck (L.) Benth. (Leguminosae). Advances in Environmental Research, v. 3, p. 207-216, 2014.

JACOBY, R. P.; LI, L.; HUANG, S.; LEE, C. P.; MILLAR, A. H.; TAYLOR, N. L. Mitochondrial composition, function and stress response in plants. Journal of Integrative Plant Biology, v. 54, p. 887 - 906, 2012.

JAIN, N.; ASCOUGH, G. D.; STADEN, J. V. A smoke-derived butenolide alleviates $\mathrm{HgCl}_{2}$ and $\mathrm{ZnCl}_{2}$ inhibition of water uptake during germination and subsequent growth of tomato - Possible involvement of aquaporins. Journal of Plant Physiology, v. 165, p. 1422 - 1427, 2008.

JAIN, R. K. Study of heavy metals effect in response to linum seed germination. African Journal of Plant Science, v. 7, n. 3, p. 93-109, 2013.

JIANG, W. et al. The effect of antibiotics on the persistence of herbicides in soil under the combined pollution. Chemosphere, v. 204, p. 303-309, 2018.

JIANG, Y. et al. Source apportionment and health risk assessment of heavy metals in soil for a township in Jiangsu Province, China. Chemosphere, v. 168, p. 1658-1668, 2017.

JUKNYS, R. et al. The impacts of heavy metals on oxidative stress and growth of spring barley. Open Life Sciences, v. 7, n. 2, p. 299-306, 2012.

KALAI, T. et al. Cadmium and copper stress affect seedling growth and enzymatic activities in germinating barley seeds. Archives of Agronomy and Soil Science, v. 60, n. 6, p. 765-783, 2014.

KARMOUS, Inès et al. Effects of copper on reserve mobilization in embryo of Phaseolus vulgaris L. Environmental Science and Pollution Research, v. 22, n. 13, p. 10159-10165, 2015.

KHANAM, R. et al. Metal (loid) s (As, $\mathrm{Hg}$, Se, $\mathrm{Pb}$ and $\mathrm{Cd}$ ) in paddy soil: Bioavailability and potential risk to human health. Science of the Total Environment, v. 699, p. 134330, 2020.

KISHOREKUMAR, A. et al. Comparative effects of different triazole compounds on growth, photosynthetic pigments and carbohydrate metabolism of Solenostemon rotundifolius. Colloids and Surfaces B: Biointerfaces, v. 60, n. 2, p. 207-212, 2007.

KO, K.S.; LEE, P. K.; KONG, I. C. Evaluation of the toxic effects of arsenite, chromate, cadmium, and copper using a battery of four bioassays. Environmental Biotechnology, v. 95, n. 5, p. 1343-1350, 2012.

$\mathrm{KOHLI}, \mathrm{S}$., K. et al. Current scenario of $\mathrm{Pb}$ toxicity in plants: unraveling plethora of physiological responses. Reviews of Environmental Contamination and Toxicology, v.249, p. 153-197, 2019.

KOIVULA, M. J.; EEVA, T. Metal-related oxidative stress in birds. Environmental pollution, v. 158, n. 7, p. 2359-2370, 2010. 
KRANNER, I.; CHEN, H.; PRITCHARD, H. W.; PEARCE, S. R.; BIRTIC, S. Internucleosomal DNA fragmentation and loss of RNA integrity during seed ageing. Plant Growth Regulation, v. 63, n.1, p. 63 - 72, 2011.

KRANNER, I.; COLVILLE, L. Metals and seeds: biochemical and molecular implications and their significance for seed germination. Environmental and Experimental Botany, v. 72, n. 1, p. 93-105, 2011.

KSHETRIMAYUM, E. et al. Regulation of seed germination and the role of aquaporins under abiotic stress. International Journal of Environment, Agriculture and Biotechnology, v. 2, n. 2, p. 238710, 2017.

KUNJAM, M. et al. Studies on selected heavy metals on seed germination and plant growth in pea plant (Pisum sativum) grown in solid medium. Journal of Pharmacognosy and Phytochemistry, v. 3, n. 5, p. 85-87, 2015.

LENTE, I. et al. Heavy metal pollution of vegetable crops irrigated with wastewater 41 Heavy Metal Pollution of Vegetable Crops Irrigated with Wastewater in Accra, Ghana. West African Journal of Applied Ecology, v. 22, n. 1, p. 41-58, 2014.

LI, Z. et al. A review of soil heavy metal pollution from mines in China: pollution and health risk assessment. Science of the total environment, v. 468, p. 843-853, 2014.

LI, Y. et al. Analysis of historical sources of heavy metals in lake taihu based on the positive matrix factorization model. International journal of environmental research and public health, v. 15, n. 7, p. 1540, 2018.

LIANG, W.; YANG, M. Urbanization, economic growth and environmental pollution: Evidence from China. Sustainable Computing: Informatics and Systems, v. 21, p. 1-9, 2019.

LIANG, Xuefeng et al. Remediation mechanisms of mercapto-grafted palygorskite for cadmium pollutant in paddy soil. Environmental Science and Pollution Research, v. 24, n. 30, p. 23783-23793, 2017.

LIU, H. Y. et al. The role of water channel proteins and nitric oxide signaling in rice seed germination. Cell research, v. 17, n. 7, p. 638-649, 2007.

LIU, J. G. et al. Effect of cadmium on seed germination and antioxidative enzymes activities in cotyledon of Solanum nigrum L. Journal of Agro-Environment Science, v. 31, n. 5, p. 880-884, 2012.

LIU, J. J.; WEI, Z.; LI, J. H. Effects of copper on leaf membrane structure and root activity of maize seedling. Botanical Studies, v. 55, p. 1-6, 2014.

LOPEZ, David et al. Insights into Populus XIP aquaporins: evolutionary expansion, protein functionality, and environmental regulation. Journal of Experimental Botany, v. 63 , n. 5, p. 2217-2230, 2012.

LORENZI, H. Árvores brasileiras: manual de identificação e cultivo de plantas arbóreas nativas do Brasil, 6a ed., Nova Odessa: Instituto Plantarum, 384 p. 2014. 
MADEJÓN, P. et al. Effects of soil contamination by trace elements on white poplar progeny: seed germination and seedling vigour. Environmental Monitoring and Assessment. v. 187, n. 11, p. 663-674, 2015.

MAGISTRALI, P. R. AÇÃO DO MERCÚRIO NO COMPORTAMENTO FISIOLÓGICO E BIOQUÍMICO NO EIXO EMBRIONÁRIO DE Schizolobium parahyba. 2016. 84fls. (Tese - Doutorado em Ciência Florestal) - Universidade Federal de Viçosa, Viçosa, 2016.

MAHAJAN, P.; KAUSHAL, J. Role of phytoremediation in reducing cadmium toxicity in soil and water. Journal of toxicology, v. 2018, 2018.

MARCOS-FILHO, J. Fisiologia de Sementes de Plantas Cultivadas. 2. ed. Londrina/PR: ABRATES, 2015, v. 1. 659 p.

MATOS, A. C. B.; BORGES, E. E. L.; SILVA, L. J. Fisiologia da germinação de sementes de Dalbergia nigra (Vell.) Allemão ex Benth. sob diferentes temperaturas e tempos de exposição. Revista Árvore, v. 39, p. 115 - 125, 2015.

MAUREL, Christophe et al. Aquaporins in plants. Physiological reviews, v. 95, n. 4, p. $1321-1358,2015$.

MIHOUB, A.; CHAOUI, A.; EL FERJANI, E. Biochemical changes associated with cadmium and copper stress in germinating pea seeds (Pisum sativum L.). Comptes rendus biologies, v. 328, n. 1, p. 33-41, 2005.

MINARI, G. D. et al. Agricultural management of an Oxisol affects accumulation of heavy metals. Chemosphere, v. 185, p. 344-350, 2017.

MITHÖFER, A.; SCHULZE, B.; BOLAND, W.; Biotic and heavy metal stress response in plants: evidence for common signals. FEBS letters, v. 566, n. 1-3, p. 1-5, 2004.

MITTLER, R.; VANDERAUWERA, S.; SUZUKI. N.; MILLER, G.; TOGNETTI, V. B.; VANDEPOELE, K.; GOLLERY, M.; SHULAEV, V.; VAN BREUSEGEM, F. ROS signaling: the new wave? Trends Plant Science, v. 16, p. 300 - 309, 2011.

MOOSAVI, S. A. et al. Effects of Some Heavy Metals on Seed Germination Characteristics of Canola (Barassica napus), Wheat (Triticum aestivum) and Safflower (Carthamus tinctorious) to Evaluate Phytoremediation Potential of These Crops. Journal of Agricultural Science, v. 4, n. 9, p. 11-19, 2012.

MORAES, Hermann. Intoxicação por mercúrio. MedClick, 23 out. 2014. Disponível em: https://www.medclick.com.br/intoxicacao-por-mercurio/. Acesso em: 10 de mar. de 2020.

MORENO, F.N.; ANDERSON, C.W.N.; STEWART, R.B.; ROBINSON, B.H. Phytofiltration of Mercury-contamined Water: Volatilisation and Plant-Accumulation aspects. Environm. and experim. Botany v. 62, p. 78-85, 2008.

MUCCIFORA, S.; BELLANI, L. M. Effects of copper on germination and reserve mobilization in Vicia sativa L. seeds. Environmental Pollution, v. 179, p. 68-74, 2013. 
MUHAMMAD, Z. I. et al. Effect of mercury on seed germination and seedling growth of Mungbean (Vigna radiata (L.) Wilczek). Journal of Applied Sciences and Environmental Management, v. 19, n. 2, p. 191-199, 2015.

MUNZUROGLU, O.; GECKIL, $\mathrm{H}$. Effects of metals on seed germination, root elongation, and coleoptile and hypocotyl growth in Triticum aestivum and Cucumis sativus. Archives of Environmental Contamination and Toxicology, v. 43, n. 2, p. 203-213, 2002.

MYŚLIWA-KURDZIEL, B. et al. Photosynthesis in heavy metal stressed plants. In: Heavy Metal Stress in Plants. Springer, Berlin, Heidelberg, 2004. p.146-181.

NAG, P.; PAUL, A.K.; MUKHERJI, S. The effects of heavy metals, zinc and mercury, on the growth and biochemical constituents of mung bean (Vigna radiata) seedlings. Botanical Bulletin of Academia Sinica, v.30, p.241-250, 1989.

NAGATI, V. B. et al. Effect of heavy metals on seed germination and plant growth on grass pea plant (Lathyrus sativus). International Journal of PharmTech Research, v. 7, n. 3, p. 528-534, 2015.

NERLING, D. Contribuição genética para qualidade fisiológica de sementes de variedades de polinização aberta de milho (Zea mays L.). 2013. 108p. (Dissertação - Mestre em Ciências/ Recursos Genéticos Vegetais.) Universidade Federal de Santa Catarina, Florianópolis, 2013.

NOGUEIRA, N. W.; RIBEIRO, N. C. C.; FREITAS, R. M. O. de.; MATUOKA, M. Y.; SOUZA, V. F. L. de. Emergência e desenvolvimento inicial de plântulas de Mimosa caesalpiniifolia Benth. Em função de diferentes substratos. Revista Agroambiente, v.6, n. 1, p. 17-24, 2012.

NONOGAKI, H.; BASSEL, G. W.; BEWLEY, J. D. Germination-still a mystery. Plant Science, v. 179, n. 6, p. 574-581, 2010.

NOVIKOVA, G. V.; TOURNAIRE-ROUXB, C.; SINKEVICHA, I. A.; LITYAGINAA, S. V.; MAUREL, C.; OBROUCHEVAA, N. Vacuolar biogenesis and aquaporin expression at early germination of broad bean seeds. Plant Physiology and Biochemistry, v. 82, p. 123 - 132, 2014.

OBROUCHEVA, N. V.; LITYAGINA, S. V.; NOVIKOVA, G. V.; SINKEVICH, I. A. Vacuolar status and water relations in embryonic axes of recalcitrant Aesculus hippocastanum seeds during stratification and early germination. AoB Plants, v. 8, p. 1 - 14, 2012.

OLIVEIRA RIOS, Camilla et al. Assessment of Iron Toxicity in Tropical Grasses with Potential for Revegetating Mined Areas. Polish Journal of Environmental Studies, v. 26, n. 5, 2017.

PAN, X. D.; WU, P. G.; JIANG, X. G. Levels and potential health risk of heavy metals in marketed vegetables in Zhejiang, China. Scientific reports, v. 6, n. 1, p. 1-7, 2016.

PASSOS, Leônidas P. Métodos analíticos e laboratoriais em fisiologia vegetal. EMBRAPA-CNPGL, 1996. 
PATRA, Manomita et al. Comparison of mercury, lead and arsenic with respect to genotoxic effects on plant systems and the development of genetic tolerance. Environmental and Experimental Botany, v. 52, n. 3, p. 199-223, 2004.

PATRA, M.; SHARMA, A. Mercury toxicity in plants. The Botanical Review, v. 66, n. 3, p. 379-422, 2000.

PATEL, A.; PANDEY, V.; PATRA, D. D. Metal absorption properties of Mentha spicata grown under tannery sludge amended soil-its effect on antioxidant system and oil quality. Chemosphere, v. 147, p. 67 - 73, 2016.

PATNAIK, A.; MOHANTY, B. K. Toxic effect of mercury and cadmium on germination and seedling growth of Cajanus cajan L. (pigeon pea). Annals of Biological Research, v. 4, n. 3, p. 123-126, 2013.

PENA, Liliana B.; AZPILICUETA, Claudia E.; GALLEGO, Susana M. Sunflower cotyledons cope with copper stress by inducing catalase subunits less sensitive to oxidation. Journal of Trace Elements in Medicine and Biology, v. 25, n. 3, p. 125129, 2011.

POURRUT, B. et al. Molecular mechanisms involved in lead uptake, toxicity and detoxification in higher plants. Heavy metal stress in plants, p. 121-147, 2013.

PUGALVENDHAN, R.; SHARAVANAN, P. S.; PRABAKARAN, G. Studies on the effect of mercury on germination and biochemical changes of ground nut [Arachis hypogaea (L). var. VRI-1] seedlings. Recent Research in Science and Technology, 2009.

QADIR, S. et al. Genotypic variation in phytoremediation potential of Brassica juncea cultivars exposed to Cd stress. Plant Science, v. 167, n. 5, p. 1171-1181, 2004.

RASCIO, N.; NAVARI-IZZO, F. Heavy metal hyperaccumulating plants: how and why do they do it? And what makes them so interesting? Plant science, v. 180, n. 2, p. 169-181, 2011.

REETHA, S. et al. Effect of cadmium nitrate and mercuric chloride in germination, growth and biochemical constituents of onion seedlings (Allium cepa L.). International Journal of Research in Biological Sciences, v. 2, n. 4, p. 182-186, 2012.

REZAEI, M. et al. Effect of $\mathrm{HgCl} 2$ on the germination of hardened rapeseed. Technical Journal of Engineering and Applied Sciences, v. 3, n. 13, p. 1162-1166, 2013.

REZANIA, S. et al. Comprehensive review on phytotechnology: heavy metals removal by diverse aquatic plants species from wastewater. Journal of hazardous materials, v. 318, p.587-599, 2016.

RODRIGUES, A. C. D.; SANTOS, A. M.; SANTOS, F. S.; PEREIRA, A. C. C.; SOBRINHO, N. M. B. A. Mecanismos de respostas das plantas à poluição por metais pesados: possibilidade de uso de macrófitas para remediação de ambientes aquáticos contaminados. Revista Virtual de Química, Niterói, v. 8, n. 1, p. 262-276, 2016. 
SADERI, S. Z. et al. The effect of different $\mathrm{Pb}$ and $\mathrm{Cd}$ concentrations on seed germination and seedling growth of Matricaria chamomilla. Advances in Environmental Biology, v. 6, n. 7, p. 1940-1943, 2012.

SANAL, F.; ŞEREN, G.; GÜNER, U. Effects of arsenate and arsenite on germination and some physiological attributes of barley Hordeum vulgare L. Bulletin of environmental contamination and toxicology, v. 92, n. 4, p. 483-489, 2014.

SANTOS, M. M.; BORGES, E.L.; ATAÍDE, G. M.; SOUZA, G.A. Germination of seeds of Melanoxylon brauna Schott under heat stress: Production of reactive oxygen species and antioxidant activity. Forests, v. 8, n. 11, p. 1-13, 2017.

SARWAR, N. et al. Phytoremediation strategies for soils contaminated with heavy metals: modifications and future perspectives. Chemosphere, v. 171, p. 710-721, 2017.

SCHUURMANS, J. A. et al. Members of the aquaporin family in the developing pea seed coat include representatives of the PIP, TIP, and NIP subfamilies. Plant Molecular Biology, v. 53, n. 5, p. 655-667, 2003.

SETHY, S. K.; GHOSH, S. Effect of heavy metals on germination of seeds. Journal of natural science, biology, and medicine, v. 4, n. 2, p. 272, 2013.

SHAHID, M. et al. Foliar heavy metal uptake, toxicity and detoxification in plants: A comparison of foliar and root metal uptake. Journal of hazardous materials, v. 325, p. 36-58, 2017.

SHAHZAD, B. et al. Nickel; whether toxic or essential for plants and environment- A review. Plant Physiology and Biochemistry, v. 132, p. 641-651, 2018.

SHANG, E. et al. Temporal-spatial trends in potentially toxic trace element pollution in farmland soil in the major grain-producing regions of China. Scientific reports, v. 9, n. 1, p. 1-14, 2019.

SHARMA, A. et al. 24-epibrassinolide restores the synthesis of proteins and amino acids in Brassica juncea L. leaves under imidacloprid stress. Journal of Horticultural Research, v. 25, n.2, p. 85-90, 2017.

SHARMA, A. et al. Jasmonic acid seed treatment stimulates insecticide detoxification in Brassica juncea L. Frontiers in plant science, v. 9, p. 1609, 2018.

SHARMA, P. et al. Reactive oxygen species, oxidative damage, and antioxidative defense mechanism in plants under stressful conditions. Journal of botany, v. 2012, 2012.

SHARMA, Pallavi; DUBEY, Rama Shanker. Lead toxicity in plants. Brazilian journal of plant physiology, v. 17, p. 35-52, 2005.

SHAW, B. P. et al. Heavy metal induced oxidative damage in terrestrial plants. In: Heavy metal stress in plants. Berlin: Springer, p.84-126, 2004. 
SIDDIQUI, M. M. et al. Toxic effects of heavy metals ( $\mathrm{Cd}, \mathrm{Cr}$ and $\mathrm{Pb}$ ) on seed germination and growth and DPPH-scavenging activity in Brassica rapa var. turnip. Toxicology and Industrial Health, v. 30, n. 3, p. 238-249, 2014.

SILVA, C. T.; JASIULIONIS, M. G. Relação entre estresse oxidativo, alterações epigenéticas e câncer. Ciência e Cultura, v. 66, p. 38 - 42, 2014.

SILVA, D. J. Análise de alimentos - métodos químicos e biológicos. Viçosa, UFV, 1990, $165 \mathrm{p}$.

SILVA, Edevaldo et al. Caracterização morfométrica e efeitos ecotoxicológicos do chumbo na germinação de sementes de Schinus terebinthifolius Raddi. Arquivos do Instituto Biológico, v. 84, p. 1-7, 2018.

SILVA, V. F.; BRITO, K. S. A.; NASCIMENTO, E. C. S.; ANDRADE, L. O.; FERREIRA, A. C. Efeito de diferentes substratos na germinação de genótipos de girassol. Revista Verde v. 9, n. 4, p. 16 - 20, 2014.

SILVEIRA, F. et al. Avoiding tailings dam collapses requires governance, partnership and responsibility. Biodiversity and Conservation, v. 28, n.7, p.1933-1934, 2019.

SINGH, H. P. et al. Lead (Pb)-inhibited radicle emergence in Brassica campestris involves alterations in starch-metabolizing enzymes. Biological trace element research, v. 144, n. 1-3, p. 1295-1301, 2011.

SINGH, S. et al. Heavy metal tolerance in plants: role of transcriptomics, proteomics, metabolomics, and ionomics. Frontiers in plant science, v.6, p.1143, 2016.

SIQUEIRA-SILVA, A. I.; RIOS, C. O.; PEREIRA, E. G. Iron toxicity resistance strategies in tropical grasses: The role of apoplastic radicular barriers. Journal of Environmental Sciences, v. 78, p. 257-266, 2019.

SOARES, C. et al. Plants facing oxidative challenges - A little help from the antioxidant networks. Environmental and Experimental Botany, v. 161, p. 4-25, 2019.

SRIVASTAVA, S.; TRIPATHI, R. D.; DWIVEDI, U. N. Synthesis of phytochelatins and modulation of antioxidants in response to cadmium stress in Cuscuta reflexa-an angiospermic parasite. Journal of plant physiology, v. 161, n. 6, p. 665-674, 2004.

SYTAR, O.; KUMAR, A.; LATOWSKI, D.; KUCZYNSKA, P.; STRZALKA, K.; PRASAD, M. N. V. Heavy metal-induced oxidative damage, defense reactions, and detoxification mechanisms in plants. Acta Physiologiae Plantarum, v. 35, p. 985 - 999, 2013.

TAIZ, L.; ZEIGER, E. Fisiologia vegetal. 5a ed. Porto Alegre, Artmed, 2013. 918 p.

TÁRRAGO, Jorge Fernández; NICOLÁS, Gregorio. Starch degradation in the cotyledons of germinating lentils. Plant physiology, v. 58, n. 5, p. 618-621, 1976.

TINÔCO, Ana Amélia Paulino et al. Avaliação de contaminação por mercúrio em Descoberto, MG. Engenharia Sanitária e Ambiental, v. 15, n. 4, p. 305-314, 2010. 
TOMESCU, D. et al. The influence of soil salinity on volatile organic compounds emission and photosynthetic parameters of Solanum lycopersicum $L$. varieties. Open Life Sciences, v. 12, n. 1, p. 135-142, 2017.

UEBEL, A. et al. Processos de Remediação do Solo Contaminado com Chumbo. Revista Caderno Pedagógico, v. 14, n. 1, 2017.

UNYAYAR, S.; CELIK, A.; CEKIC, F. O.; GOZEL, A. Cadmium-induced genotoxicity, cytotoxicity and lipid peroxidation in Allium sativum and Vicia faba. Mutagenesis, $\mathrm{V}$. 21, p. $77-81,2006$.

VALKO, M. et al. Redox-and non-redox-metal-induced formation of free radicals and their role in human disease. Archives of toxicology, v. 90, n. 1, p. 1-37, 2016.

VANDER WILLIGEN, C. et al. Expression and inhibition of aquaporins in germinating Arabidopsis seeds. Plant and Cell Physiology, v. 47, n. 9, p. 1241-1250, 2006.

VESELOVA, T. V. et al. Hypoxia and imbibition injuries to aging seeds. Russian journal of plant physiology, v. 50, n. 6, p. 835-842, 2003.

WANG, P. F. et al. Evaluating the Impact of Long Term Hydrodynamic Conditions on the Release of Metals from Contaminated Sediments in Taihu Lake, China. Journal of Environmental Informatics, v. 27, n. 1, 2016.

WANG, Y. et al. Characteristics of groundwater discharge to river and related heavy metal transportation in a mountain mining area of Dabaoshan, Southern China. Science of the total environment, v. 679, p. 346-358, 2019.

WU, S.; ZHOU, S.; LI, X. Determining the anthropogenic contribution of heavy metal accumulations around a typical industrial town: Xushe, China. Journal of Geochemical Exploration, v. 110, n. 2, p. 92-97, 2011.

XIA, F.; WANG X.; LI, M.; MAO, P. Mitochondrial structural and antioxidant system responses to aging in oat (Avena sativa L.) seeds with different moisture contentes. Plant Physiology and Biochemistry, v. 94, p. 122 - 129, 2015.

YADAV, K. K. et al. Mechanistic understanding and holistic approach of phytoremediation: a review on application and future prospects. Ecological engineering, v. 120, p. 274-298, 2018.

YÁÑEZ-ESPINOSA, L. et al. Effect of heavy metals on seed germination and seedling development of Nama aff. stenophylla collected on the slope of a mine tailing dump. International Journal of Phytoremediation, v.22, n.14, p. 1448-1461, 2020.

YAN, D. et al. The functions of the endosperm during seed germination. Plant and Cell Physiology, v. 55, n. 9, p. 1521-1533, 2014.

YANG, Q. et al. A review of soil heavy metal pollution from industrial and agricultural regions in China: Pollution and risk assessment. Science of the total environment, v. 642 , p. $690-700,2018$. 
YONAR, M. E., YONAR, S. M. Changes in selected immunological parameters and antioxidant status of rainbow trout exposed to malachite green (Oncorhynchus mykiss, Walbaum, 1792). Pesticide Biochemistry and Physiology, v. 97, p. 19 - 23, 2010.

YUAN, X. et al. A real filed phytoremediation of multi-metals contaminated soils by selected hybrid sweet sorghum with high biomass and high accumulation ability. Chemosphere, v. 237, p. 124536, 2019.

YUAN, Z. et al. Potentially toxic trace element contamination, sources, and pollution assessment in farmlands, Bijie City, southwestern China. Environmental monitoring and assessment, v. 189, n. 1, p. 1-10, 2017.

ZHANG, F. Q.; WANG, Y. S.; LOU, Z. P.; DONG, J. D. Effect of heavy metal stress on antioxidative enzymes and lipid peroxidation in leaves and roots of two mangrove plant seedlings (Kandelia candel and Bruguiera gymnorrhiza). Chemosphere, v. 67, p. 44 50, 2007.

ZHOU, Z.S.; HUANG, S.Q.; GUO, K.; MEHTA, S.K.; ZHANG, P.C.; YANG, Z.M. Metabolic Adaptations to Mercury-Induced Oxidative Stress in Roots of Medicago sativa L. Journal of Inorganic Biochemistry. v. 101, p. 1-9, 2007. 